\title{
1 Root water gates and not changes in root structure provide 2 new insights into plant physiological responses and 3 adaptations to drought, flooding and salinity
}

Institution addresses:

aBordeaux Sciences AGRO, UMR1391 ISPA INRA, 1 Cours du général de Gaulle 33175 Gradignan Cedex, France.

12 bicholas School of the Environment, Duke University, Durham, NC 27708, USA.

13 'Department of Forestry and Environmental Resources, North Carolina State University, Raleigh, NC 14 27606, USA.

15 Departments of Biology and Environmental Studies, Hollins University, Roanoke, VA 24020, USA.

16 'elanning, Design and the Built Environment, Clemson University, Clemson, SC 29634, USA.

17 fUniversité de Lorraine, INRA, UMR 1434 Silva, 54000, Nancy, France.

18 'Department of Biology, Wake Forest University, Winston-Salem, NC 27109, USA. USA.

${ }^{j}$ Warnell School of Forestry and Natural Resources, University of Georgia, Athens, GA 30602, USA.

\section{Corresponding author:}

Jean-Christophe Domec / jc.domec@,duke.edu

\section{Running title:}

aquaporins regulate plant response to environmental stresses

\section{Word count:}

31 Text body without M\&M: 4361 words

327 figures, 6 in color.

332 Tables 


\section{Highlight}

40 New insights on organ hydraulics reveal that plant responses to drought, flooding and salinity is

41 highly dynamic, reflecting a balance between species adaptive capacity and root aquaporin.

\section{Abstract}

44 The influence of aquaporin (AQP) activity on plant water movement remains unclear, especially

45 in plants subject to unfavorable conditions. We applied a multitiered approach at a range of plant

46 scales to (i) characterize the resistances controlling water transport under drought, flooding and

47 flooding plus salinity conditions; (ii) quantify the respective effects of AQP activity and xylem

48 structure on root $\left(\mathrm{K}_{\text {root }}\right)$, stem $\left(\mathrm{K}_{\text {stem }}\right)$ and leaf $\left(\mathrm{K}_{\text {leaf }}\right)$ conductances, and (iii) evaluate the impact of

49 AQP-regulated transport capacity on gas exchange. We found that drought, flooding and flooding-

50 salinity reduced $\mathrm{K}_{\text {root }}$ and root AQP activity in Pinus taeda, whereas $\mathrm{K}_{\text {root }}$ of the flood-tolerant

51 Taxodium distichum did not decline under flooding. The extent of the AQP-control of transport

52 efficiency varied among organs and species, ranging from $35 \%-55 \%$ in $\mathrm{K}_{\text {root }}$ to $10 \%-30 \%$ in $\mathrm{K}_{\text {stem }}$

53 and $\mathrm{K}_{\text {leaf. }}$ In response to treatments, $\mathrm{AQP}-$ mediated inhibition of $\mathrm{K}_{\text {root }}$ rather than changes in xylem

54 acclimation controlled the fluctuations in $\mathrm{K}_{\text {root. }}$ The reduction in stomatal conductance and its

55 sensitivity to vapor pressure deficit were direct responses to decreased whole-plant conductance

56 triggered by lower $\mathrm{K}_{\text {root }}$ and larger resistance belowground. Our results provide new mechanistic

57 and functional insights on plant hydraulics that are essential to quantifying the influences of future

58 stress on ecosystem function.

60 Key words: aquaporin activity, anatomy, conductances, flooding, leaf water relations, plant

61 hydraulics, water stress 


\section{Introduction}

68 There is scientific consensus that the Earth's climate is changing at a geologically unprecedented

69 rate and that human activities are a contributing factor, indicated by the National Academy of

70 Sciences survey on climate change (NAS, 2020), and bolstered by a recent IPCC report

71 (Oppenheimer et al., 2019). Due to a combination of seawater thermal expansion and melting of

72 glaciers and polar ice sheets, global sea level rose $0.17 \mathrm{~m}$ over the $20^{\text {th }}$ century and is projected to

73 rise by at least $0.35 \mathrm{~m}$ by 2100 (Peltier, 2002). Coastal forests are among the world's most

74 biologically diverse and productive ecosystems, but unfortunately are also the most vulnerable to

75 sea level rise (SLR; Kirwan and Gedan, 2019). In addition to increased flooding, SLR is globally

76 expected to foster high salinities into tributary freshwater areas of the coastal zones (Bhattachan

77 et al., 2018). At the same time of being subject to increased salinity, those threatened ecosystems

78 undergo periodic droughts exposing coastal forests to low soil water availability (DeSantis et al.,

79 2007). Understanding forest responses to SLR therefore requires the determination of

80 physiological response mechanisms to drought, flooding and flooding plus salinity.

Scientists have a broad-scale understanding of plant adjustment and tolerance to flooding

82 and salinity along environmental gradients and the bulk of recent work in plants has been crucial

83 in distinguishing adaptive plant strategies (Kirwan and Gedan, 2019). One of the most

84 characteristic traits of wetland plants is aerenchyma, a specialized tissue made of intercellular gas-

85 filled spaces that improves the storage and diffusion or oxygen. Overall, the physiological

86 responses of plants to salt stress and flooding are similar in many ways (Allen et al., 1996; Munns,

87 2002), but the mechanisms by which plants deal with these stressors differ across species (Munns

88 and Tester, 2008). The main consensus is that the primary responses of plants to flooding and salt

89 is inhibition of root hydraulic conductance (Loustau et al., 1995; Rodríguez-Gamir et al., 2012). 
90 In turn, this reduction in water uptake capacity reduces photosynthesis and growth due to the

91 closure of stomata (McLeod et al., 1996; Munns and Tester, 2008). However, there are no studies

92 that have focused on variation in hydraulic traits in contrasting species in terms of adaptive

93 strategies and root physiological responses to full inundation, limiting our understanding of how

94 they are linked to leaf- and whole-plant-level water transport, which limits our ability to predict

95 forest ecophysiological response to SLR and climate change.

Water flow in the soil-plant-atmosphere continuum (SPAC) is determined by the hydraulic

97 conductance of soil and plant tissues, which characterizes the structural capacity of the whole plant

98 to move water (Tyree and Zimmermann, 2002). Hydraulic conductance $\left(\mathrm{K}_{\text {plant }}\right)$ is an important

99 factor predicting gas exchange, transpiration, plant water status, growth rate and resistance to

100 environmental stresses (Sperry, 2003; Addington et al., 2004; Brodribb and Holbrook, 2003;

101 McCulloh et al., 2019). The partitioning of $K_{\text {plant }}$ along the water transport path is very variable,

102 not only among species, but also diurnally and among plant organs (Ye and Steudle, 2006; Johnson

103 et al., 2016). Approximately $50-60 \%$ of the whole-plant hydraulic resistances $\left(1 / \mathrm{K}_{\text {plant }}\right)$ are located

104 in the root system, which shows the outstanding importance of this organ within the flow path (see

105 review by Tyree and Zimmermann 2002). Peripheral organs such as leaves and roots have been

106 proposed as possible replaceable hydraulic fuses of the SPAC during stress, uncoupling stems

107 hydraulically from transpiring surfaces and soil (Hacke et al., 2000; Sperry, 2003; Domec et al.,

1082009 Johnson et al., 2016). Quantifying the relative contribution of $\mathrm{K}_{\text {root }}$ to $\mathrm{K}_{\text {plant }}$ and how it varies

109 under drought, flooding, and flooding plus salinity is thus essential for understanding how these

110 stressors influence photosynthesis and stomatal conductance $\left(g_{s}\right)$ and their sensitivity to climatic

111 variables. In addition, mechanistic depiction of variation in $K_{\text {plant }}$ and its impact on $g_{\mathrm{s}}$, and the 
112 sensitivity of $g_{s}$ to prominent environmental drivers, requires isolating the main resistances to plant

113 water flow, and their dynamics in response to abiotic stress factors, which has rarely been done.

114 Most research on abiotic stresses has focused on aboveground organs and neglected

115 physiological responses of the roots, especially in woody plants. This is surprising because

116 important processes of plant tolerance are located in the roots and also because roots are the first

117 organs to be affected by water stress, flooding and salinity (Krauss et al., 1999). In radial and axial

118 roots axes, resistance to water flow depends on root anatomy (Knifer and Fricke, 2011), whereas

119 in the radial component it is also a function of protein water channels, or aquaporins (AQP), that

120 regulate the resistance of the transcellular pathway (Chaumont et al., 2005; Gambetta et al., 2017).

121 Aquaporins are imbedded in the plasma and vacuolar membranes of most root cell types and form

122 pores that are highly selective for water (Tornroth-Horsefield et al., 2006). In crop plants AQP

123 chemical inhibitors (i.e. mercuric chloride or hydroxyl radicals) demonstrated that AQP down-

124 regulation is the principal cause of alterations of the radial pathway, resulting in a decrease in $\mathrm{K}_{\text {root }}$

125 (Ehlert et al., 2009; Knifer and Fricke, 2011; Maurel and Nacry 2020). Despite a recent flurry of

126 studies, compared to reference plants used in molecular studies such as corn, tobacco and

127 Arabidopsis (Siefritz et al., 2002; Lopez et al., 2003; Bramley et al., 2009; Sade et al., 2010; Tan

128 and Zwiazek, 2019), the importance of species differences in AQP regulation in woody plants and

129 its effect within the SPAC is still poorly understood (McElrone et al., 2007; Gambetta et al., 2013;

130 Johnson et al., 2014; Rodriguez-Gamir et al., 2019).

131 Better information on physiological functioning of forest species in stressed environments

132 is needed to develop adaptive management strategies that will help protect threatened coastal

133 ecosystems (Carmichael and Smith, 2016). To fully understand the impacts of SLR on plant

134 adaptation, the influence of abiotic stresses on root hydraulics must be evaluated with respect to 
135 the entire capacity of the plant to move water. This is especially relevant for seedlings, which have

136 low physiological capacity to tolerate many stressors (Niinemets, 2010), impacting species

137 persistence under changing conditions (Megonigal and Day, 1992; Brodersen et al., 2019). In that

138 framework, our first objective was to characterize the vascular conductances that control water

139 movement through the plant system under drought, flooding, and flooding plus salinity stresses.

140 Our second objective was to quantify the effects of AQP activity on plant organs and partition the

141 antagonistic effects of AQP and xylem structure on conductances. Our third objective was to

142 evaluate a hypothesized correlation between leaf-level gas exchange and AQP regulation of water

143 transport under varying environmental conditions. Using contrasting species, we tested the

144 hypotheses that decrease in hydraulic conductance between treatments 1) is controlled by AQP

145 activity rather than by a change in root xylem structure with greater declines in stress-intolerant

146 plants, and in roots than in stems and leaves; and 2) is optimized in plants experiencing lower AQP

147 inhibition, such that $\mathrm{K}_{\text {root }}$ exerts greater control on $\mathrm{K}_{\text {plant, }}$, which in turn affect $\mathrm{g}_{\mathrm{s}}$ and carbon

148 assimilation when environmentally stressed.

\section{Material and Methods}

\section{Plant material and greenhouse experiments}

152 We used 50 one-year-old Taxodium distichum L. and Pinus taeda L. half-sib seedlings supplied 153 by ArborGen Inc. (Ridgeville, SC, USA). At the beginning of the spring season (late March), the 154 seedlings were repotted in 19 liters commercial plant pots filled with a Fafard-4P soil mixture 155 composed of sphagnum peat moss (50\%), bark (25\%), vermiculite $(15 \%)$ and perlite (Fafard Inc., 156 Agawam, MA, USA). This mixture was representative of the soil texture and organic matter 157 content of soils found in coastal forested wetlands. Potted plants were maintained in a greenhouse 
with a 16-h photoperiod where daytime mean temperature and relative humidity were kept at $23 \pm 3$

$159{ }^{\circ} \mathrm{C}$ and $55 \pm 6 \%$, respectively. Before the treatments were applied, all 50 plants were watered three

160 times a week. Eight weeks after the beginning of the experiment 36 plants were randomly separated

161 into four groups (control, droughted, flooded, flooded plus salt) and were surrounded and buffered

162 by the 14 plants that were not used for the measurements. These treatments were intended to

163 represent stresses related to SLR and periodic droughts exposing coastal forests, and thus the soil

164 salinity treatment with no flooding was not studied. Those single-factor experiments were

165 conducted simultaneously and applied for 35 days (Rodriguez-Gamir et al., 2019). Control plants

166 were irrigated with 2 liters of water twice per week, which was enough to saturate the substrate.

167 For the drought treatment, plants were never irrigated from the start until the end of the experiment

168 (Rodriguez-Gamir et al., 2019). Flooding and flooding plus salinity was imposed by submerging

169 the seedlings to the root-collar (3 cm above the surface) without draining the pots (Pezeshki, 1992).

170 The salinity treatment (at a concentration of $4 \mathrm{~g}^{-1}$, or 4 parts per thousand) was prepared using a

171 commercial seawater mixture $\left(24 \mathrm{~g}^{-1} \mathrm{NaCl} ; 11 \mathrm{~g}^{-1} \mathrm{MgCl}_{2}-6 \mathrm{H}_{2} \mathrm{O} ; 4 \mathrm{~g}^{-1} \mathrm{Na}_{2} \mathrm{SO}_{4} ; 2 \mathrm{~g} 1^{-1} \mathrm{CaCl}_{2}-\right.$

$\left.1726 \mathrm{H}_{2} \mathrm{O} ; 0.7 \mathrm{~g}^{-1} \mathrm{KCl}\right)$.

173

174 Hydraulic conductance of root, shoot and whole plant

175 Five weeks after the treatments were applied, root $\left(K_{\text {root }}\right)$, shoot $\left(K_{\text {shoot }}\right)$ and stem $\left(K_{\text {stem }}\right)$ hydraulic 176 conductance were directly measured using a Hydraulic Conductance Flow Meter (HCFM; Tyree 177 et al., 1993) (Dynamax Inc., Houston, TX, USA). Hydraulic parameters were determined in six 178 loblolly pine and five bald cypress seedlings per treatment, and conductance values for a given 179 plant were obtained from the same plant. To minimize the potential impact of diurnal periodicity 180 on hydraulic conductance, all measurements were taken between $1000 \mathrm{hrs}$ and $1200 \mathrm{hrs}$ and under 
181 the same environmental conditions (temperature of $22^{\circ} \mathrm{C}$, and relative humidity of $60 \%$ ). During

182 HCFM measurements, the leaves were submerged in water to maintain constant temperature and

183 prevent transpiration. To measure $\mathrm{K}_{\text {root }}$ and $\mathrm{K}_{\text {shoot }}$ the plants were cut $5 \mathrm{~cm}$ above the soil surface

184 and the cut ends of the shoots and roots were connected to the HCFM. This instrument perfuses

185 degassed water through root or shoot system by applying pressure to a water-filled bladder

186 contained within the unit. $K_{\text {root }}$ was determined between 2 and 4 minutes after shoot decapitation,

187 thus minimizing measurement errors to less than 10\% (Vandeleur et al. 2014; Rodriguez-Gamir et

188 al., 2019; see also Supplementary Figure 1). The flow rate of water through root or shoot was

189 determined under transient mode (Yang and Tyree, 1994), which consists in measuring flow rate

190 under increasing pressure applied by a nitrogen gas cylinder. Transients were also performed on

191 shoots after removal of leaves to determine $\mathrm{K}_{\text {stem. }}$. The applied pressure gradually rose from 0 to

$192450 \mathrm{kPa}$ over the course of approximately 1 minute and the flow rate at each pressure value was

193 logged every 2 seconds using the Dynamax software. Hydraulic conductance (K) was then

194 calculated using the formula: $\mathrm{K}=\mathrm{Q}_{\mathrm{v}} / \mathrm{P}$; where $\mathrm{Q}_{\mathrm{v}}$ is the volumetric flow rate $\left(\mathrm{kg} \mathrm{s}^{-1}\right)$ and $\mathrm{P}$ is the

195 applied pressure (MPa). Hydraulic conductance was standardized to values for $25{ }^{\circ} \mathrm{C}$ to account

196 for the effects of temperature on water viscosity. Because the HCFM operates under high pressure,

197 the measured $K_{\text {root }}$ and $K_{\text {shoot }}$ represent maximum values of conductances, that is in the absence of

198 embolized conduits. At the end of the measurements, all-sided leaf area of the shoots was

199 determined with an LI-3100 leaf area meter (Li-Cor, Inc., Lincoln, NE, USA), and conductance

200 values were expressed on leaf specific area basis (Yang and Tyree, 1994). All plant biomass

201 fractions were then harvested and dried at $70^{\circ} \mathrm{C}$ for 48 hours and weighed. Further, mass-specific

202 root hydraulic conductance (Kroot-biomass) was calculated by normalizing $\mathrm{K}_{\text {root }}$ by root dry mass. 

were sampled) and stem tracheids were visualized by perfusing the decapitated samples with $0.1 \%$ toluidine blue and imaged at 90-180x magnification using a digital camera mounted on a widefield zoom stereo microscope (ZM-4TW3-FOR-9M AmScope, USA). Tracheid diameter was measured

207 along four 4 radials rows per sample using an image analysis software (Motic Images version 3.2,

208 Motic Corporation, China). In addition, the presence or absence of aerenchyma was assessed on 4

209 lateral roots per sample, which included the two used for tracheid size determination (no 210 aerenchyma was present in the stems).

211 Whole plant hydraulic resistance was calculated as in Domec et al. (2016)

$$
1 / \mathrm{K}_{\text {plant }}=1 / \mathrm{K}_{\text {root }}+1 / \mathrm{K}_{\text {shoot }}
$$

213 and resistances of the shoot components $\left(1 / \mathrm{K}_{\text {stem }}\right.$ and $\left.1 / \mathrm{K}_{\text {leaf }}\right)$ were calculated from the difference

214 between resistances before and after removal of each leaf. Hydraulic conductance and resistance

215 are reciprocals, and the latter is used for partitioning the resistances in the root-to-leaf continuum, 216 and the former for examining the coordination between plant hydraulics and gas exchange.

\section{Aquaporin contribution to hydraulic conductances}

219 We quantified the AQP contribution to $\mathrm{K}_{\text {root }}$ and $\mathrm{K}_{\text {shoot }}$ (and its components) and $\mathrm{K}_{\text {plant }}$ using

220 hydroxyl radicals $(* \mathrm{OH})$ produced using the Fenton reaction (solution made by equal mixing of

$2210.6 \mathrm{mM} \mathrm{H}_{2} \mathrm{O}_{2}$ and $3 \mathrm{mM} \mathrm{FeSO}_{4}$ ) to inhibit AQP activity (Ye and Steudle, 2006; McElrone et al.,

222 2007). Hydroxyl radicals has been shown to be less toxic and above all more effective in blocking

223 water channels than mercuric chloride (Henzler and Steudle, 2004). Conductances with AQP

224 function inhibited were measured by introducing approximately $18 \mathrm{ml}$ of $* \mathrm{OH}$ solution, instead of

225 water, into the existing compression couplings connected to the sample and the HCFM (McElrone 

2011; Rodriguez-Gamir et al., 2019), the effect of $* \mathrm{OH}$ on conductivity was effective and

228 reversable in less than 6 minutes when radicals were replaced with distilled water (Supplementary

229 Fig. 1). Six transient curves per sample were constructed with the HCFM: two before inhibiting

230 AQP activity, two after AQP inhibition, and two final ones after flushing the samples with water

231 only to reassessed flow rate with no AQP inhibition. We calculated the AQP contribution to Kroot,

$232 \mathrm{~K}_{\text {shoot }}\left(\mathrm{K}_{\text {stem }}\right.$ and $\left.\mathrm{K}_{\text {leaf }}\right)$ and $\mathrm{K}_{\text {plant }}$ as the difference between initial conductance and conductance

233 after AQP inhibition, divided by the initial conductance (Rodriguez-Gamir et al., 2019).

234 From measurements of conductances before and after inhibiting AQP activity, we were

235 able to calculate whether the departure in values from control was due to either the xylem-only

236 (structural changes in xylem conduits) or the AQP-only part of the hydraulic pathway. For a given

237 stress applied, the structural part of the hydraulic pathway reducing conductance was calculated

238 by dividing the difference in conductance between control and treatment after inhibiting AQP 239 activity by the difference in conductance between control and treatment without inhibiting AQP 240 activity. The AQP effect was taken as 1 minus the structural effect.

\section{Gas exchange and water potential}

243 Net photosynthesis (A) and stomatal conductance $\left(g_{s}\right)$ were measured with a Li-Cor 6400 (Li-Cor,

244 Inc., Lincoln, NE, USA). For each leaf, the chamber was set to match prevailing environmental

245 conditions assessed immediately prior to the measurement: atmospheric $\mathrm{CO}_{2}$ concentration (390-

$246410 \mathrm{ppm}$ ), relative humidity (46-59\%), photosynthetically active radiation (PAR; 1600-1800 $\mu \mathrm{mol}$

$\left.247 \mathrm{~m}^{-2} \mathrm{~s}^{-1}\right)$, and leaf temperature $\left(21-26^{\circ} \mathrm{C}\right)$. All gas exchange results were expressed on an all-sided

248 leaf area basis, and only fully-expanded healthy-appearing needles of the same age were picked 
249 for analysis. Maximum (light saturated) photosynthetic capacity $\left(\mathrm{A}_{\text {sat }}\right)$ was measured on 4 green

250 branchlets needles per seedling grown in the upper third of the plants. Immediately after the gas

251 exchange measurements were performed, leaf water potential ( $\left.\Psi_{\text {leaf }}\right)$ was measured using a pressure

252 chamber (PMS Ins., Albany, OR, USA). To assess maximum (least negative) $\Psi_{\text {leaf, two branchlets }}$

253 per individual from each treatment were sampled at predawn (between 05:00 hrs and 06:00 hrs).

254 Net photosynthesis versus intercellular $\mathrm{CO}_{2}$ concentrations (A-Ci curves) were measured

255 at $25{ }^{\circ} \mathrm{C}$ leaf temperature, $60 \pm 10 \%$ relative humidity and $1600 \mu \mathrm{mol} \mathrm{m} \mathrm{m}^{-1} \mathrm{PAR}$. The chamber

$256 \mathrm{CO}_{2}$ concentrations were set to ambient and sequentially lowered to $50 \mathrm{ppm}$ and then to $1500 \mathrm{ppm}$.

257 These data were used to estimate the maximum Rubisco carboxylation $\left(\mathrm{V}_{\mathrm{cmax}} 25\right)$, the maximum

258 electron transport $\left(J_{\max 25}\right)$, and the dark respiration $\left(\mathrm{R}_{\mathrm{d} 25}\right)$ rates according to Farquhar et al. (1980).

260 Field hydraulic and canopy conductance

261 Two contrasting sites were used to determine field values of $\mathrm{K}_{\text {plant }}$ and $\mathrm{g}_{\mathrm{s}}$ under typical field 262 conditions, droughted and flooded conditions of large trees growing in intact forests. Soil salinity 263 never occurred at the field sites to our knowledge. The first study site is a forested wetland located 264 at the Alligator River National Wildlife Refuge, on the Albemarle-Pamlico Peninsula of North 265 Carolina, USA $\left(35^{\circ} 47^{\prime} \mathrm{N}, 7^{\circ} 54^{\prime} \mathrm{W}\right)$. This research site was established in November 2008, and 266 includes a 35-m instrumented tower for eddy covariance flux measurements, a 267 micrometeorological station, and 13 vegetation plots spread over a $4 \mathrm{~km}^{2}$ area (Miao et al. 2013; 268 Domec et al., 2015). The forest type is mixed hardwood swamp forest (>100-year-old); the 269 overstory is predominantly composed of water tupelo (Nyssa aquatica L.) that represents $39 \%$ of 270 the basal area and an even mix of red maple (Acer rubrum L.), bald cypress and loblolly pine. The 
271 canopy of this site is fairly uniform with heights ranging from $16 \mathrm{~m}$ to $21 \mathrm{~m}$, and with leaf area

272 index peaking at $4.0 \pm 0.3$ in early July.

273 The second, drier site $\left(35^{\circ} 11^{\prime} \mathrm{N}, 76^{\circ} 11^{\prime} \mathrm{W}\right)$ located within the lower coastal plain, mixed

274 forest province of North Carolina (Domec et al., 2009). This 100-ha mid-rotation (23-year-old)

275 loblolly pine stand (US-NC2 in the Ameriflux database) was established in 1992 and has an

276 understory comprised of other woody species such as sparse red maple and bald cypress trees.

277 Artificial drainage lowers the height of the water table, improving site access and increases

278 productivity, especially during winter months (Domec et al., 2015).

279 At both sites, canopy conductance was derived from sapflow measurements and thus

280 comprises the total water vapor transfer conductance from the 'average' stomata of the canopy.

281 Sapflow was measured at breast height using thermal dissipation probes inserted in two flood-

282 adapted species (bald cypress and water tupelo) and two others not adapted to flooding (red maple

283 and loblolly pine) (see Domec et al., 2015 for further description of the sites and the methodology

284 used). Note that water tupelo was only present at the wetland site. Stomatal conductance of the

285 plants measured in the field was calculated from transpiration and vapor pressure deficit (VPD),

286 using the simplification of the inversion of Penman-Monteith model (Ward et al., 2013). To

287 analyze the effect of $K_{\text {plant }}$ on $g_{s}, K_{\text {plant }}$ from field and greenhouse samples was calculated from the

288 slope of the relationship between diurnal variation in $\Psi_{\text {leaf }}$ and transpiration (Loustau et al., 1995).

289 Changes in $\Psi_{\text {leaf }}$ from dawn to mid-afternoon were quantified with a pressure chamber (PMS,

290 Albany, OR) on six to eight leaves collected from each tree equipped with sapflow sensors

291 Oren et al. (1999) showed that under saturated light, the decrease in $\mathrm{g}_{\mathrm{s}}$ with increasing VPD

292 is proportional to $\mathrm{g}_{\mathrm{s}}$ at low VPD. Therefore, the sensitivity of the stomatal response to VPD when 
293 PAR was above $800 \mu \mathrm{mol} \mathrm{m} \mathrm{m}^{-2} \mathrm{~s}^{-1}$ (light-saturated $\mathrm{g}_{\mathrm{s}}$ ) was determined by fitting the data to the

294 functional form:

295

$$
\mathrm{gs}_{\mathrm{s}}=\mathrm{b}-\mathrm{a} \ln (\mathrm{VPD})
$$

296 where $\mathrm{b}$ is $\mathrm{g}_{\mathrm{s}}$ at $\mathrm{VPD}=1 \mathrm{kPa}$ (hereafter designated as reference or maximum canopy-averaged

297 stomatal conductance, $\mathrm{g}_{\mathrm{s}-\mathrm{max}}$ ), and a is the rate of stomatal closure and reflects the sensitivity of $\mathrm{g}_{\mathrm{s}}$

298 to VPD $\left[\mathrm{dg}_{\mathrm{s}} / \mathrm{d} \ln \mathrm{VPD}\right.$, in $\left.\mathrm{mmol} \mathrm{m} \mathrm{m}^{-2} \mathrm{~s}^{-1} \ln (\mathrm{kPa})^{-1}\right]$. We propose to use this framework where VPD 299 and light intensity are fixed to investigate the nature of the relationship between $\mathrm{K}_{\mathrm{plant}}$ and $\mathrm{g}_{\mathrm{s}-\mathrm{max}}$, 300 and how this relationship affects the sensitivity of $g_{s}$ to VPD.

\section{Statistical analyses}

303 All measured parameters were tested using multiple analysis of variance with species, treatments, 304 and AQP activity taken as factors. Mean separation was performed using the Tukey's procedure at $30595 \%$ confidence level. Statistical analyses were run using SAS (Version 9.4, Cary, NC, USA) and 306 curve fits using SigmaPlot (version 12.5, SPSS Inc. San Rafael, CA, USA).

308 Results

$309 \quad$ Plant biomass

310 All treatments significantly reduced loblolly pine (Pinus taeda L.) total biomass $(p<0.01$; Table

311 1), whereas for the flood-tolerant bald cypress (Taxodium distichum L.) only the drought and the

312 flooded plus salinity treatments had a negative effect on growth $(p<0.037)$. This decrease in plant

313 growth was mainly attributed to a reduction in root and stem biomass in bald cypress $(p<0.032)$,

314 and in leaf and stem biomass in loblolly pine $(p<0.01)$. Despite this reduction in plant size, the

315 fine root to leaf mass ratio of bald cypress was only affected in the flooding plus salinity treatment, 
316 whereas in loblolly pine it was stimulated by $25 \%$ and $55 \%$ in the flooding and the flooding plus

317 salinity conditions, respectively. All stresses decreased leaf mass per area (LMA) in loblolly pine

$318(p<0.02)$. In bald cypress LMA was only negatively affected by the drought and by the flooded

319 plus salinity treatments $(p<0.01)$. Field measurements indicated that unlike loblolly pine and red

320 maple (Acer rubrum L.), flooded bald cypress and water tupelo (Nyssa aquatica L.) grew as rapidly

$321(p>0.65)$ as trees subjected to periodic or non-flooded conditions (Supplementary Fig. 2).

322

323 Effect of flooding and salinity on the partitioning of hydraulic conductance

324 All treatments decreased whole-plant hydraulic conductance $\left(\mathrm{K}_{\text {plant }}\right)$ in loblolly pine $(p<0.05)$,

325 whereas bald cypress was only affected by the drought and the flooding plus salinity treatment

326 (Fig. 1). In both species the strongest decrease in root (Kroot) and shoot (Kshoot) hydraulic

327 conductances were measured for plants subjected to flooding plus salinity. It should be noted that

328 flooding alone did not affect any of the conductances in bald cypress. When loblolly pines were

329 flooded, even $\mathrm{K}_{\text {root }}$ on a root-mass basis ( $\mathrm{K}_{\text {root_biomass }}$ ) dropped significantly (by $45 \%$ ), whereas $\mathrm{K}_{\text {root }}$

330 or Kroot_biomass of the flood-tolerant bald cypress did not (Table 2; Fig.1).

331 The overall decline in K

332 in loblolly pine, and by root resistance only in bald cypress (Fig. 2). Under control conditions,

333 roots represented between $35 \%$ and $45 \%$ of whole-plant resistance $\left(1 / \mathrm{K}_{\text {plant }}\right)$, and under treatments

334 this partitioning increased to more than $50 \%(p=0.038)$ in loblolly pine, which was paralleled by

335 a reduction in leaf resistance from $35 \%$ to $15 \%(p=0.023)$. In bald cypress, only the flooded plus

336 salt treatment increased the predominance of root resistance, which was accompanied by a

337 decrease in the contribution of leaf and stem to the overall whole-plant resistance. 
340 The reduction in $K_{\text {root }}$ and $K_{\text {plant }}$ between control and the other treatments (Fig. 2) was mainly

341 caused by a reduction in AQP activity rather than by a change in root anatomy (Table 1; Fig. 3).

342 Even when $\mathrm{K}_{\text {root }}$ was calculated on a root-biomass basis ( $\mathrm{K}_{\text {root-biomass }}$ ), the inhibition of AQP activity

343 led to similar values of $K_{\text {root-biomass }}$ (AQP-inhibited $K_{\text {root_biomass }}$ in Table 2) across all treatments

$344(p>0.47)$ in bald cypress, and for the flooded treatment $(p=0.87)$ in loblolly pine. Nonetheless, in

345 loblolly pine seedlings, AQP-inhibited Krootbiomass decreased by $31 \%(p=0.042)$ and $45 \%$

$346(p=0.028)$ in the drought and flooded plus salt treatments, respectively, but that was still less than

347 the overall reduction in $\mathrm{K}_{\text {root_biomass }}(52 \%$ and $66 \%$, respectively), indicating that changes in

348 Krootbiomass were mostly driven by the inhibition of AQP. This reduction in $\mathrm{K}_{\text {root_biomass }}$ in loblolly

349 pine mirrored the decrease in root and stem tracheid diameter in the drought and flooded plus salt

350 treatments (Table 1). In bald cypress, tracheid size was not affected by treatment, but aerenchyma

351 production was stimulated under flooded conditions (Table 1).

While blockage of AQP reduced hydraulic conductance, the extent of the decrease varied

353 among organs and species (Fig. 3). Root AQP activity in loblolly pine decreased $(p<0.001)$ from

$35442 \%$ under controlled conditions, to less than 5-17\% in the different treatments, which was the

355 driver of the decline in whole-plant AQP contribution (Fig. 4A). In this species, we found that

356 flooding and flooding plus salinity reduced the AQP activity of the whole plants from $32 \%$ to less

357 than $6 \%(p<0.01)$. In bald cypress only the drought and flooded plus salt treatments reduced

$358(p<0.02)$ AQP contribution to $\mathrm{K}_{\text {root }}$ or $\mathrm{K}_{\text {plant }}($ Fig. 4B). For that species, the inhibition of AQP in

359 the flooding treatment did not affect $(p=0.95) \mathrm{K}_{\text {root }}$ or $\mathrm{K}_{\text {leaf. }}$ In both species, drought also had a

360 significant effect on AQP contribution to $\mathrm{K}_{\text {leaf }}$ with a decrease from $17 \%$ to $9 \%(p<0.03)$ in

361 loblolly pine, and from $44 \%$ to $23 \%(p<0.001)$ in bald cypress. In both species there was no

362 treatment effect on the contribution of AQP activity to $\mathrm{K}_{\text {stem }}(p>0.42)$. 

under saturated light) for bald cypress was only negatively affected by drought and the flooding plus salt treatment (Table 2). In loblolly pines, $\mathrm{g}_{\mathrm{s}-\mathrm{max}}$ differed under flooded and flooded plus salt treatments, experiencing the smallest and the largest stomatal closure, respectively. Photosynthetic rate of both species was also negatively affected by treatments $(p<0.04)$, with the strongest reduction for the drought and flooded-salt treatments (Table 2). The disruption of photosynthesis concurred with a reduction in rubisco carboxylating enzyme activities and maximum electron transport rate $\left(\mathrm{VC}_{\max 25}\right.$ and $\mathbf{J}_{\max 25}$, respectively; Table 2). Similarly, across species dark respiration rates were only affected by the flooded plus salt treatments.

374 grown in the field, a 50\% reduction in $\mathrm{K}_{\text {plant }}$ was accompanied by a $37 \%$ decline in $\mathrm{g}_{\mathrm{s}-\mathrm{max}}$ (Fig.

375 5A). There was indeed no difference $(p=0.33)$ in the relationship between $\mathrm{g}_{\mathrm{s}-\mathrm{max}}$ and $\mathrm{K}_{\mathrm{plant}}$ for seedlings growing in greenhouse and mature trees in the field. Species differences were apparent

377 in $K_{\text {plant, }}$ with higher values in bald cypress and red maple. Flooded loblolly pine exhibited the 378 same level of reduced $\mathrm{K}_{\text {plant }}$ as water-stressed plants. In red maple, permanently flooded conditions 379 reduced water uptake capacity more than two-fold, and this species exhibited higher hydraulic 380 limitation and $\mathrm{g}_{\mathrm{s}-\mathrm{max}}$ in flooded than in drought-stressed conditions. However, bald cypress and 381 water tupelo (circles and diamonds in Fig. 5A, respectively), which are species found in 382 permanently wet soils, did not experience more than $15 \%$ decline in $\mathrm{g}_{\mathrm{s}-\max }$ under flooded 383 conditions. The sensitivity of $\mathrm{g}_{\mathrm{s}}$ to VPD was linearly related to $\mathrm{g}_{\mathrm{s}-\mathrm{max}}$ (Fig. 5B) and $\mathrm{K}_{\text {plant }}$ 384 (Supplementary Fig. 3). Stomatal conductance declined in response to increasing VPD, and the 385 magnitude of the reduction varied over the measurement period as shown by the decline in $\mathrm{g}_{\mathrm{s}-\mathrm{max}}$. 
The slope of the relationship between $g_{s-m a x}$ and the sensitivity of $g_{s}$ to VPD $(0.62 \pm 0.04)$ was not different $(p>0.99)$ than the previously reported generic value of 0.60 based on a hydraulic model that assumes tight stomatal regulation of $\Psi_{\text {leaf }}($ Oren et al., 1999).

Maximum $g_{s}$ and stomatal sensitivity to VPD decreased linearly with increasing the contribution of root hydraulic resistance $\left(1 / \mathrm{K}_{\text {root}}\right)$ to $1 / \mathrm{K}_{\text {plant }}$ for both species (Fig. 6). Those negative relationships appeared also to be identical across treatments with a $50 \%$ increase in resistance belowground resulting in a $56 \%$ reduction in $\mathrm{g}_{\mathrm{s} \_ \text {max }}$ and in a $65 \%$ decrease in stomatal sensitivity to VPD.

The decrease in $g_{\text {s_max }}$ and $A_{\text {sat }}$ were linked to a decrease in AQP contribution to root conductance among treatments and also species $(p<0.039$; Fig. 7). Although weaker, those relationships still held when whole-plant AQP activity was compared to gas exchange, and a 25 $\%$ decrease in AQP contribution to $\mathrm{K}_{\text {plant }}$ was predicted to reduce $\mathrm{g}_{\mathrm{s} \_ \text {max }}$ by $38 \%$ and $\mathrm{A}_{\text {sat }}$ by $30 \%$.

\section{Discussion}

In US coastal regions from Maryland to Texas that are vulnerable to SLR (Titus and Richman,

401 2001; Kirwan and Gedan, 2019), many species such as bald cypress, water tupelo, red maple and loblolly pine are ecologically dominant and commercially important. The first two species are fully

403 adapted to partial or total soil flooding and the other species are common to forest communities of 404 estuarine woodlands (Pezeshki, 1992; Keeland and Sharitz, 1995). Bald cypress seedlings 405 generally tolerate flooding, but marked with an initial reduction in growth (Allen et al., 1996).

406 However, within 3 to 5 years, seedlings generally recover from the stress imposed by developing 407 pneumatophores (Megonigal and Day, 1992), explaining why flooded trees may grow as rapidly 408 as trees subjected to non-flooded conditions (Supplementary Fig. 2). However, before this root 
409 formation occurs, the influence of AQP on control of plant water movement and gas exchanges is

410 needed and reflected in our results (Fig 4; Fig.7).

412 Aquaporin activity appears to be essential in species-specific tolerance to stress

413 Our results highlight the integrated nature of hydraulics across the whole plant and emphasized

414 the contributions of structural and physiological components to conductance (Bramley et al., 2009;

415 Maurel and Nacry, 2020). Drought, flooding and flooding plus salinity treatments caused a

416 significant shift in hydraulic resistance away from stem and leaves to the roots, because of

417 differential transmembrane AQP activity and not because of changes in the apoplastic hydraulic

418 pathway (xylem diameter) (Table 1, Fig. 3 and see AQP-inhibited Kroot_biomass in Table 2). During

419 stress, some structural and anatomical changes also occurred as seen by the decrease in either leaf,

420 stem or root biomass under drought or flooded plus salt treatments, affecting for the latter treatment

421 root to leaf area ratio in both species (Table 1). However and unlike the role played by AQP, those

422 structural changes provided only minute adjustments in xylem hydraulic conductance

423 (conductance once AQP activity was inhibited) and did not explain the whole decrease in

424 conductance and thus the physiological mechanisms controlling water transport through the root

425 (Table 2; Fig. 3). Both loblolly pine and bald cypress were highly susceptible to the combined

426 stress of flooding plus salinity which lends support to the role of saltwater intrusion in the

427 formation of coastal ghost forests, since bald cypress is also dying in these forests (Kirwan and

428 Gedan, 2019). Lower predawn $\Psi_{\text {leaf }}$ were expected with higher salinity because the lower osmotic

429 potential of the medium (4 ppm corresponding to an osmotic potential of $0.31 \mathrm{MPa}$ ) likely

430 increased leaf tissue ionic concentration (Allen et al., 1996). This excess of ions disrupted

431 photosynthesis and inhibited carboxylating enzyme activities (Table 2), which in turn contributed 
432 to inhibited root or leaf growth, and the production of new aerenchymatous roots in the flood433 adapted species (Table 1).

434 These findings may shed light on the adaptive advantages of altering AQP activity in 435 response to environmental stresses (Maurel and Nacry, 2020). Regarding drought, lowering AQP

436 activity in roots should lead to larger $\Psi_{\text {leaf }}$ gradients, inducing stomata to close more rapidly.

437 Reducing water channel activity can then be seen as a means to reduce water loss when soil water 438 availability is low (McLean et al., 2011). In the case of flooding, the resulting decrease in $\mathrm{K}_{\text {root }}$ 439 observed in the flood-intolerant species (such as loblolly pine used here) could also limit water 440 transport to the leaves, causing stomatal closure and thus protecting the integrity of the whole 441 hydraulic system until non-stressed conditions resume (Else et al., 2001). Loblolly pine is known 442 to be tolerant to low salinity and short-term flooding (Poulter et al., 2008), and our experiment 443 showed that this species reduced significantly gas exchange under these conditions, but to levels

444 that were not lethal (Table 2). The negative impact of flooding on plants is a consequence of the 445 low solubility of oxygen in water (Leyton and Rousseau, 1958), leading to anoxia (Kozlowski, 446 1997). The tight coupling of AQP functioning to the drop in cell energy (due to oxygen deprivation 447 and acidosis) suggests that short-term adjustments in tissue hydraulics are critically needed during 448 the early stages of the anoxic stress to balance water uptake with water loss (Tan et al., 2019). 449 Long-term metabolic adaptation to flooding is generally characterized by the decrease in 450 belowground biomass to limit oxygen deficiency, but one of the most adaptive features of plants 451 of wetland ecosystems is aerenchymatous tissues characterized by intercellular gas-filled spaces 452 that improve the storage and diffusion of oxygen. Unlike the adjustment in root biomass or xylem 453 anatomy that can take more than 2 months (Krauss et al., 1999) and was not observed in any of 454 the two seedlings (Table 1), intercellular air spaces, which were present after 5 weeks of flooding 
455 in bald cypress, likely played a vital role in maintaining root uptake and preventing the AQP-

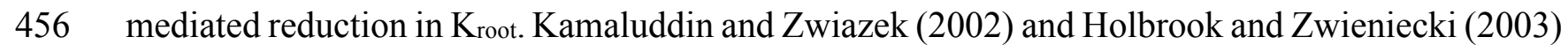

457 have also proposed that anoxia-induced AQP down-regulation may prevent the transport of

458 ethylene precursors away from the root, thereby favoring the accumulation of ethylene to trigger

459 the differentiation of root aerenchymas, especially in adapted species such as bald cypress (Table

460 1). Salinity added to the flooding stress may trigger larger AQP inhibition, so that advective salt

461 flow to the root surface may be minimized (Azaizeh and Steudle, 1991). In the short term (a few

462 hours following exposure to flooding or flooding plus salinity), it has been shown that plants

463 respond to osmotic shock by reduced AQP activity (Martinez-Ballesta et al., 2000; Rodríguez-

464 Gamir et al., 2012), which in our case was followed by reduced $\mathrm{K}_{\text {root, }}$ most likely as an adaptive

465 strategy to eliminate water loss from the roots under conditions of low osmotic potential.

466 Finally, it can also be hypothesized that the role of AQP may in fact not concern the primary

467 response of the plant to stress, but its recovery performance (Siefritz et al., 2002). Stimulation of

468 specific AQP suggested that "gating" in response to salt stress involved not only the reduction in

469 water channels, but also an enhancement in the internalization of specific AQPs (raft-associated

470 pathway), putatively becoming active once stress is relieved (Li et al., 2011).

472 Root hydraulics as related to whole plant water transport and gas exchange

473 One of the objectives of our study was to evaluate a hypothesized correlation between leaf gas

474 exchange and root hydraulics as influenced by AQP activity. The decline in $\mathrm{g}_{\mathrm{s} \_\max }$ (and it is

475 sensitivity to VPD) and photosynthesis was strongly related to the increase in root resistance due

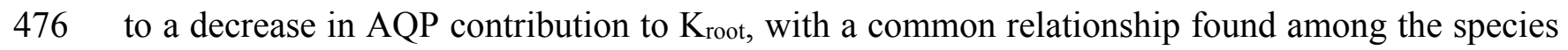

477 despite important differences in treatment responses (Figs. 6 and 7). In non woody plants, it has 
478 been suggested that abscisic acid (ABA) accumulation in leaves may be responsible for stomatal

479 closure in flooded plants (Castonguay et al., 1993; Else et al., 2001). However, in woody plants

480 the marked reduction in $\mathrm{g}_{\mathrm{s}}$ in flooded seedlings does not seem to be induced by ABA, since a

481 significant reduction in $\mathrm{g}_{\mathrm{s}}$ appeared a week after stressors were applied (unpublished data;

482 Rodríguez-Gamir et al., 2012), whereas the increase in ABA in leaves is generally detected 4-5

483 weeks later (Zhang and Zhang, 1994; Rodríguez-Gamir et al., 2012). Maximum gs and Kplant were

484 tightly coordinated in plants growing in the field or in greenhouse (Fig. 5). Changes in $K_{\text {plant, }}$ driven

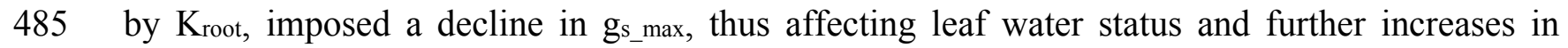

486 transpirational water loss and carbon assimilation. Midday $\Psi_{\text {leaf }}$ did not change during the flooding

487 treatment, highlighting the adaptive role of stomatal closure in counteracting leaf dehydration

488 (Meinzer, 2003). Furthermore, our data indicate that flooded pines exhibited the same level of

489 reduced $\mathrm{K}_{\text {plant }}$ as water stressed plants. Field data showed that red maple exhibited higher hydraulic

490 limitation and higher $\mathrm{g}_{\mathrm{s}-\mathrm{max}}$ in flooded than in water stressed conditions, indicating that species

491 differences exist in the response to flooding. In contrast, bald cypress and water tupelo regulated

492 very efficiently the closure of stomata, thus adjusting the evaporative water losses to the water

493 uptake capacity of roots and the resulting decrease in $K_{\text {plant }}$ (Fig. 5).

Our results also showed that the sensitivity of $g_{s}$ to VPD was mostly attributable to the

495 variation in $\mathrm{g}_{\mathrm{s}-\mathrm{max}}$, which is consistent with the isohydric regulation of $\Psi_{\text {leaf }}$ induced by $\mathrm{K}_{\text {plant }}($ Oren

496 et al., 1999). Stomata responded to VPD in a manner consistent with protecting xylem integrity

497 and thus the capacity for water transport (Domec et al., 2009; McCulloh et al., 2019). Future

498 climate change is expected to increase temperature and therefore VPD in many regions

499 (Oppenheimer et al., 2019). Stomatal acclimation to VPD as affected by drought, flooding and

500 flooding plus salinity could potentially have a large impact on the global water and carbon cycles. 
501 Here we measured that in forested wetlands global plant transpiration responses to future climate

502 will probably not differ from expectations based on the well-known relationship between $g_{s}$ and

503 VPD (Oren et al., 1999). To improve climate predictions of warming effects on transpiration for

504 plants subjected to different abiotic stresses, our results indicated that modelers could potentially

505 allow for predictable shifts in $\mathrm{g}_{\mathrm{s}}$ under water stress but also flooded conditions, combined with the

506 use of single coefficient conveying $g_{s}$ sensitivity to VPD.

Woody species responses to flooding and flooding plus salinity are wide-ranging and can

508 change based on the life-history stage of a plant. Seedlings are generally more sensitive to salinity

509 while mature plants may show a wider range of tolerance (Kozlowski, 1997). However, when our

510 field and greenhouse observations were analyzed together, some common responses were

511 observed (Fig. 5), highlighting the need for integrating data on seedlings and mature plants in

512 future studies on wetland adaptation to SLR and its restoration (Carmichael and Smith, 2016).

\section{Conclusion}

515 Our study provides new functional and mechanistic insights on plant hydraulics by showing that

516 the components of $\mathrm{K}_{\text {plant }}$ are highly dynamic, reflecting a balance between species adaptive

517 capacity and AQP functioning. Neither species tolerated flooding plus salinity. In loblolly pine,

518 high water uptake was largely mediated by active transport through AQP, but was easily disrupted

519 by drought, flooding and salinity. In bald cypress, a flooded-tolerant species, AQP contribution to

520 water transport was less sensitive overall and did not respond to flooding. Under controlled

521 conditions, AQP activity and xylem structure were colimiting root water transport. However, in

522 response to environmental factors, except again for the flooding treatment in bald cypress, AQP

523 functioning rather than changes in xylem structure or biomass allocation controlled the fluctuations 
524 in $\mathrm{K}_{\text {root, }}$ and thus in $\mathrm{K}_{\text {plant. }}$ The decline in $\mathrm{K}_{\text {leaf }}$ was rather the consequence of both a decrease in

525 AQP activity and in structural changes. An important challenge was also to integrate the AQP-

526 mediated reduction in $\mathrm{K}_{\text {root }}$ within the mutual interactions of roots and shoots and its putative effect

527 on gas exchange. As such, across species and treatments, the reduction in $g_{\text {s }}$ and its sensitivity to

528 VPD appeared to be direct responses to decreased $K_{\text {plant }}$ and was influenced by AQP contribution

529 to water transport.

\section{Data availability statement}

The data supporting the findings of this study are available from the corresponding author (JeanChristophe Domec) upon request.

Funding information: This work was supported by a grant USDA-AFRI (\#2012-00857), the National Science Foundation - Division of Integrative Organismal Systems (\#1754893), and by the ANR projects CWSSEA- SEA-Europe, and PRIMA-SWATCH. The USFWS Alligator River operations.

Author contributions: J.-C.D. and D.M.J. conceived the original screening and research plans; J.-C.D., D.M.J., R.W. and M.J.C. performed the hydraulics experiments, A.T.O., M.J.C. and R.W. performed the gas exchange experiments; J.S.K., J.-C.D., A.N., and G.M. performed field experiments; W.K.S. provided plant materials; J-C.D. and D.M.J. analyzed the data and wrote the article with contributions of all the authors.

\section{References}

Addington RN, RJ Mitchell, R Oren and LA. Donovan (2004) Stomatal sensitivity to vapor pressure deficit and its relationship to hydraulic conductance in Pinus palustris. Tree Physiology 24:561-569.

Allen JA, Pezeshki S R, Chambers J L (1996) Interactions of flooding and salinity stress on baldcypress (Taxodium distichum). Tree Physiology 16: 307-313.

Almeida-Rodriguez A.M., Hacke U.G, Laur J. (2011) Influence of evaporative demand on aquaporin expression and root hydraulics of hybrid poplar. Plant, Cell Enviro 34:1318-1331 

E.A. Ury, T.K. BenDor, and J. P. Wright (2018). Evaluating the effects of land-use change and future climate change on vulnerability of coastal landscapes to salwater intrusion. Elementa Sciences of the Anthropocene 6:62.

Bramley H, Turner NC, Turner DW, Tyerman SD. 2009. Roles of morphology, anatomy, and aquaporins in determining contrasting hydraulic behavior of roots. Plant Physiology 150, 348364.

Brodersen CR, Germino MJ, Johnson DM, Reinhardt K, Smith WK, Resler LM, Bader MY, Sala A, Kueppers LM, Broll G, Cairns DM, Holtmeier F-K and Wieser G (2019) Seedling Survival at Timberline Is Critical to Conifer Mountain Forest Elevation and Extent. Front. For. Glob. Change 2:9. DOI: 10.3389/ffgc.2019.00009

Brodribb TJ and NM Holbrook (2003) Stomatal closure during leaf dehydration, correlation with other leaf physiological traits. Plant Physiology 132, 2199-2173.

Carmichael MJ and Smith WK (2016) Growing season ecophysiology of Taxodium distichum (L.) Rich. (bald cypress) saplings in a restored wetland: a baseline for restoration practice. Botany 94: 1115-1125.DOI: 10.1139/cjb-2016-0147.

Castonguay Y., Nadeau P, Simard R.R (1993) Effects of flooding on carbohydrate and ABA levels in roots and shoots of alfalfa, Plant Cell Environ 16: 695-702.

Chaumont F, Moshelion M, Daniels MJ. 2005. Regulation of plant aquaporin activity. Biology of the Cell 97: 749-764

Church JA, P Huybrechts, M Kuhn, K Lambeck, MT Nhuan, D Qin and PL Woodworth. (2001) Changes in sea level. In: Houghton, J.T., Ding, Y., Griggs, D.J., Noguer, N., Van der Linden, P.J. \& Xiaou, D. (eds.) Climate change 2001: The scientific basis. Cambridge University Press, Cambridge, UK.

DeSantis LRG, Bhotika S, Williams K, Putz FE (2007) Sea-level rise and drought interactions accelerate forest decline on the Gulf Coast of Florida, USA. Global Change Biology 13: 23492360 .

606

Domec J-C, A Noormets, JS King, G Sun G, SG McNulty et al. (2009) Decoupling the influence of leaf and root hydraulic conductances on stomatal conductance and its sensitivity to vapor pressure deficit as soil dries in a drained loblolly pine plantation. Plant, Cell Enviro 32:980-991.

Domec J.C., J. S King, E. Ward, A. C. Oishi, S. Palmroth, A. Radecki, D. M. Bell, G. Miao, M. Gavazzi, D. M. Johnson, S.G. McNulty, G. Sun, A. Noormets (2015) Conversion of natural forests to managed forest plantations decreases tree resistance to prolonged droughts. Forest Ecology and Management 355:58-71. 
Domec, J.-C., Palmroth S., Oren. R (2016) Effects of Pinus taeda leaf anatomy on vascular and extravascular leaf hydraulic conductance as influenced by $\mathrm{N}$-fertilization and elevated $\mathrm{CO}_{2}$. Journal of Plant Hydraulics 3e007.

Ehlert C, C Maurel, F Tardieu and C Simonneau (2009) Aquaporin-Mediated Reduction in Maize Root hydraulic conductivity impacts cell turgor and leaf elongation even without changing transpiration. Plant Physiology 150: 1093-1104.

Else M.A., Coupland D., Dutton L. \& Jackson M.B (2001) Decreased root hydraulic conductivity reduces leaf water potential, initiates stomatal closure and slows leaf expansion in flooded plants of castor oil (Ricinus communis) despite diminished delivery of ABA from the roots to shoots in xylem sap. Physiologia Plantarum 111, 46- 54.

Farquhar, G.D., S. von Caemmerer and J.A. Berry (1980) A biochemical model of photosynthetic CO2 fixation in leaves of C3 species. Planta 149, 78-90

Gambetta G.A., Fei J., Rost T.L., Knipfer T., Matthews M.A., Shackel K.A., Walker M.A., McElrone A.J. (2013) Water uptake along the length of grapevine fine roots: developmental anatomy, tissue-specific aquaporin expression, and pathways of water transport. Plant Physiology 163, 1254-1265.

Gambetta GA, Knipfer T, Fricke W, McElrone AJ (2017) Aquaporins and root water uptake. In: F Chaumont, S Tyerman (eds) Plant Aquaporins, Signaling and Communication in Plants. Springer Verlag Berlin, Heidelberg, pp 133-153

Hacke UG, JS Sperry, BE Ewers, DS Ellsworth, KVR Schäfer, and R Oren (2000) Influence of soil porosity on water use in Pinus taeda. Oecologia 124:495-505.

Henzler T, Steudle E. 2004. Oxidative gating of water channels (aquaporins) in Chara by hydroxyl radicals. Plant Cell \& Environemnt 27: 1184-1195.

Holbrook NM and MA Zwieniecki (2003) Plant biology: water gate. Nature 425:361

Johnson D.M., M. Sherrard, J.C. Domec, R.B. Jackson (2014) Role of aquaporin activity in regulating deep and shallow root hydraulic conductance during extreme drought. Tree Structure and Function 28:1223-1331. Palmroth S., Domec J.-C. (2016) A test of the hydraulic vulnerability segmentation hypothesis in angiosperm and conifer tree species. Tree Physiology 36: 983-993.

Kamaluddin M and JJ Zwiazek (2002) Ethylene enhance water transport in hypoxic aspen. Plant Physiology 128:962-969. 
Keeland, BD and R R Sharitz (1995). Seasonal growth patterns of Nyssa sylvatica var. biflora, Nyssa aquatica, and Taxodium distichum as affected by hydrologic regime. Canadian Journal of Forest Research 25:1084-1096.

Kirwan ML, Gedan KF (2019) Sea-level driven land conversion and the formation of ghost forests. Nature Climate Change: 9: 450-457.

Knifer T and Fricke W (2011) Water uptake by seminal and adventitious roots in relation to whole-plant water flow in barley (Hordeum vulgare L.). Journal Experimental Botany 62:71733.

Kozlowski TT. (1997) Responses of woody plants to flooding and salinity. Tree Physiology Monograph 1:1-29.

Krauss KW, JL Chambers, JA Allen, B Luse and A DeBosier. (1999) Root and shoot responses of Taxodium distichum seedlings subjected to saline flooding. Environmental and Experimental Botany 41:15-23.

Leyton L and Z Rousseau. (1958) Root growth of tree seedlings in relation to aeration. In:

Martinez-Ballesta M.C., Martinez V., Carvajal M (2000) Regulation of water channel activity in whole roots and in protoplasts from roots of melon plants grown under saline conditions.

Maurel C, Nacry P (2020) Root architecture and hydraulics converge for acclimation to changing

Loustau D, S Crepeau, MG Guye, M Sartore, E Saur. (1995) Growth and water relations of three geographically separate origins of maritime pine (Pinus pinaster) under saline conditions. Tree Physiology 15: 569-576 Australian Journal of Plant Physiology 27, 685-691. water availability. Nature Plants 6:744-749.

McCulloh K., Domec J-C, Johnson D.M., Smith D.D., Meinzer F.C. (2019) A dynamic yet vulnerable pipeline: Integration and coordination of hydraulic traits across whole plants. Plant, Cell \& Environment 42: 2789-2807 DOI: 10.1111/pce.13607.

McElrone A. J., Bichler, J., Pockman, W. T., Addington, R. N., Linder, C. R., \& Jackson, R. B. (2007). Aquaporin-mediated changes in hydraulic conductivity of deep tree roots accessed via caves. Plant, Cell \& Environment 30, 1411-1421. 
McLean E.H., Ludwig, M., Grierson, P. F. 2011. Root hydraulic conductance and aquaporin abundance respond rapidly to partial root-zone drying events in a riparian Melaleuca species. New Phytologist. 192, 664-675.

McLeod KW, JK McCarron, and WH Conner (1996) Effects of flooding and salinity on photosynthesis and water relations of four Southeastern Coastal Plain forest species. Wetlands Ecology and Management 4: 31-42.

Megonigal JP and FP Day (1992) Effects of flooding on root and shoot production of bald cypress

Meinzer FC (2003) Functional convergence in plant responses to the environment. Oecologia 134:1-11.

Miao, G., Noormets, A., Domec, J.-C., Trettin, C.C., McNulty, S.G., Sun, G., King, J.S (2013) The effect of water table fluctuation on soil respiration in a lower coastal plain forested wetland in the southeastern US. J. Geophys. Res.: Biogeosci. 118, 1748-1762.

Munns R (2002) Comparative physiology of salt and water stress. Plant Cell Envir 25:239-50.

Munns R and M Tester (2008) Mechanisms of salinity tolerance. Annu. Rev. Plant Biol. 2008. 59:651-81

NAS (2020) Climate Change: Evidence and Causes: Update 2020. Washington, DC: The National Academies Press. 36p. https://doi.org/10.17226/25733.

Niinemets $\mathbf{U}$ (2010) Responses of forest trees to single and multiple environmental stresses from seedlings to mature plants: Past stress history, stress interactions, tolerance and acclimation. Forest Ecology and Management 260: 1623-1639.

Oppenheimer, M., B.C. Glavovic, J. Hinkel, R. van de Wal, A.K. Magnan, A. Abd-Elgawad, R. Cai, M. Cifuentes-Jara, R.M. DeConto, T. Ghosh, J. Hay, F. Isla, B. Marzeion, B. Meyssignac, and Z. Sebesvari. (2019) Sea Level Rise and Implications for Low-Lying Islands, Coasts and Communities. In: IPCC Special Report on the Ocean and Cryosphere in a Changing Climate [H.-O. Pörtner, D.C. Roberts, V. Masson-Delmotte, P. Zhai, M. Tignor, E. Poloczanska, K. Mintenbeck, A. Alegría, M. Nicolai, A. Okem, J. Petzold, B. Rama, N.M. Weyer (eds.)].

Oren R, Sperry JS, Katul GG, Pataki DE, Ewers BE, Phillips N and KVR. Schäfer (1999) Survey and synthesis of intra- and interspecific variation in stomatal sensitivity to vapour pressure deficit. Plant Cell Environment 22:1515-1526.

Peltier WR (2002) On eustatic sea level history: last glacial maximum to Holocene. Quaternary Science Reviews 21: 377-396.

Pezeshki SR (1992) Response of Pinus taeda to soil flooding and salinity. Annales des Sciences Forestières 4: 149-159. 
Poulter B, NL Christensen and Q.S. Song (2008) Tolerance of Pinus taeda and Pinus serotina to low salinity and flooding: Implications for equilibrium vegetation dynamics. Journal of Vegetation Science 19: 15-22.

Rodríguez-Gamir, J., Ancillo, G., Legaz, F., Primo-Millo, E. \& Forner-Giner, M.A (2012) Influence of salinity on PIP gene expression in citrus roots and its relationship with root hydraulic conductance, transpiration and chloride exclusion from leaves. Environmental and experimental botany 78, 163-166

Rodriguez-Gamir J., Xue J., Clearwater M.J., Meason D.F., Clinton P.W. \& Domec J.-C (2019) Aquaporin regulation in roots controls plant hydraulic conductance, stomatal conductance and leaf water potential in Pinus radiata under water stress. Plant, Cell \& Environment 42:717729. DOI: $10.1111 /$ pce. 13460.

Ross MS and JJ O'Brien (1994) Sea-level rise and the reduction in pine forests in the Florida Keys. Ecological Applications 4:144-156.

Tan X, Zwiazek JJ. (2019) Stable expression of aquaporins and hypoxia-responsive genes in adventitious roots are linked to maintaining hydraulic conductance in tobacco (Nicotiana tabacum) exposed to root hypoxia. PLoS One. 14(2):e0212059.

Siefritz F, MT Tyree, C Lovisolo, A Schubert and R Kaldenhoff (2002) PIP1 plasma membrane aquaporins in tobacco; from cellular effects to function in plants. The Plant cell 14:869-876.

Sperry JS. (2003) Evolution of water transport and xylem structure. International Journal of Plant Science 164: 115-127.

Titus JG and C. Richman (2001) Maps of lands vulnerable to sea level rise: modeled elevations along the US Atlantic and Gulf coasts. Climate Research 18: 205-228.

Törnroth-Horsefield S, Y Wang, K Hedfalk, U Johanson, M Karlsson, E Tajkhorshid, R Neutze and P. Kjellbom (2006) Structural mechanism of plant aquaporin gating. Nature 439:688694

Tyree MT, Sinclair B, Lu P, Granier A. 1993. Whole shoot hydraulic conductance in Quercus species measured with a new high-pressure flow meter. Ann. For Sc. 50: 417-423.

Tyree MT and MH. Zimmermann (2002) Xylem Structure and the Ascent of Sap (second ed), Springer, New York, NY. aquaporins. Plant, Cell \& Environment 37, 520-538. ttps://doi.org/10.1111/pce.12175 
787 Ward, E.J., Oren, R., Bell, D.M., Clark, J.S., McCarthy, H.R., Seok-Kim, H., Domec, J.-C 788 (2013) The effects of elevated CO2 and nitrogen fertilization on stomatal conductance estimated

791 Yang, S. and M.T. Tyree (1994) Hydraulic architecture of Acer saccharum and A. rubrum: 792 comparison of branches to whole trees and the contribution of leaves to hydraulic resistance. J. 793 Exp. Bot. 45:179-186.

Ye, Q., \& Steudle, E (2006). Oxidative gating of water channels (aquaporins) in corn roots. Plant, Cell \& Environment 29, 459-470. https://doi.org/10.1111/j.1365-3040.2005.01423.x

Zhang J., Zhang X (1994) Can early wilting of old leaves account for much of the ABA 


\section{Figure captions}

802 Figure 1: Mean values (+SE) of hydraulic conductances (solid bars) in root, shoot and whole 803 loblolly pine $(n=6)$ and bald cypress $(n=5)$ plants growing in control, droughted, flooded and

804 flooded + salt conditions. Crosses indicate a significant difference between control and any of the 805 treatments $(p<0.05)$. Hashed bars represent values of hydraulic conductance following aquaporin 806 inhibition i.e. the xylem-only part of the hydraulic pathway.

808 Figure 2: Partitioning of hydraulic resistances (1/conductance) of loblolly pine and bald cypress 809 organs in control, flooded and flooded + salt conditions. Note that in all cases root and leaves 810 represented more than $70 \%$ of total whole plant resistance.

812 Figure 3: Effect (shown in percent) of either the xylem-only (structural changes in xylem conduits) 813 or the aquaporin-only (AQP) part of the hydraulic pathway on the decrease in loblolly pine and 814 bald cypress hydraulic conductance between control and drought, flooded, and flooded plus 815 salinity treatments (absolute values of conductances are seen in Fig. 1). For a given stress applied, 816 the structural part of the hydraulic pathway reducing conductance was calculated by dividing the 817 difference in conductance between control and treatment after inhibiting AQP activity by the 818 difference in conductance between control and treatment without inhibiting AQP activity. The 819 AQP effect was taken as 1 minus the structural effect. Bars with patterns represent treatments that 820 did not induce significant difference in conductance ( $p>0.05$; flooded condition for bald cypress).

822 Figure 4: Aquaporin (AQP) contribution to root, stem, leaf and whole-plant hydraulic 823 conductances in (A) loblolly pine $(n=6,+S E)$ and (B) bald cypress seedlings $(n=5,+S E)$ growing 824 under control, water-stressed, flooded, and flooded plus salinity conditions. Crosses indicate a 825 significant difference in whole-plant AQP contribution between control and any of the treatments $826(p<0.05)$.

828 Figure 5: (A) Linear relationship between the maximum (reference) stomatal conductance $\left(g_{\mathrm{s}}\right.$ at 829 vapor pressure deficit $=1 \mathrm{kPa})$ and $(\mathrm{B})$ plant hydraulic conductance $\left(\mathrm{K}_{\text {plant }}\right)$ and between the 830 sensitivity of stomatal conductance to vapor pressure deficit ( $\left.\mathrm{dg}_{\mathrm{s}} / \mathrm{dln}_{\mathrm{VPD}}\right)$ and $\mathrm{g}_{\mathrm{s}-\mathrm{max}}$ of plant 831 species growing under control, water-stressed, flooded, and flooded plus salinity conditions. 
832 Circles, diamonds, squares and triangles represent bald cypress, water tupelo, loblolly pine and red

833 maple, respectively. Crossed-filled symbols represent mature plants growing in the field, non-

834 crossed symbols represent bald cypress and loblolly pine seedlings from the greenhouse

835 experiment. In $(\mathrm{B})$, the red line $($ slope $=0.6)$ indicates the theoretical slope between stomatal

836 conductance at VPD $=1 \mathrm{kPa}$ and stomatal sensitivity to VPD that is consistent with the role of

837 stomata in regulating minimum leaf water potential (Oren et al. 1999).

839 Figure 6: Maximum stomatal conductance ( $\left.\mathrm{g}_{\mathrm{s}-\mathrm{max}}\right)$ and the sensitivity of stomatal conductance to

840 vapor pressure deficit $\left(\mathrm{dg}_{\mathrm{s}} / \mathrm{d} \ln \mathrm{VPD}\right)$ versus percent of hydraulic resistance in roots of bald cypress

841 (Bald.) and loblolly pine (L.-Pine) seedlings growing under control, water-stressed, flooded, and

842 flooded plus salinity conditions.

844 Figure 7: Maximum stomatal conductance $\left(\mathrm{g}_{\mathrm{s}-\mathrm{max}}\right)$ and Light saturated photosynthetic rate $\left(\mathrm{A}_{\mathrm{sat}}\right)$

845 versus aquaporin (AQP) contribution to root, or whole-plant hydraulic conductances of bald 846 cypress (Bald.) and loblolly pine (L.-Pine) seedlings growing under control, water-stressed, 847 flooded, and flooded plus salinity conditions. 
Table 1. Plant, root (fine and coarse), stem and leaf dry masses (g), as well as mean tracheid diameters (Dt_stem; Dt_root), fine-root to leaf mass ratio (Root_fine/Leaf), and leaf mass per area (LMA) for the different treatments of Taxodium distichum ( $\mathrm{n}=5$, $+\mathrm{SE})$ and Pinus taeda $(\mathrm{n}=6,+\mathrm{SE})$. The presence (Yes - and the percentage of roots affected) or absence (No) of root aerenchyma (intercellular air spaces) observed 5 weeks after initiating the treatments is also indicated.

\begin{tabular}{|c|c|c|c|c|c|c|c|c|}
\hline & \multicolumn{2}{|l|}{ Control } & \multicolumn{2}{|l|}{ Drought } & \multicolumn{2}{|l|}{ Flooded } & \multicolumn{2}{|c|}{ Flooded plus Salt } \\
\hline & T. distichum & P. taeda & T. distichum & P. taeda & T. distichum & P. taeda & T. distichum & P. taeda \\
\hline Plant (g) & $13.9 \pm 1.1 \mathrm{C}$ & $10.7 \pm 0.4 \mathrm{~B}$ & $9.9 \pm 0.9 \mathrm{AB}$ & $9.1 \pm 0.4 \mathrm{~A}$ & $11.7 \pm 1.0 \mathrm{BC}$ & $9.5 \pm 0.6 \mathrm{~A}$ & $9.7 \pm 0.8 \mathrm{AB}$ & $7.9 \pm 0.8 \mathrm{~A}$ \\
\hline Root (g) & $6.1 \pm 0.4 \mathrm{~B}$ & $4.7 \pm 0.4 \mathrm{~A}$ & $4.4 \pm 0.5 \mathrm{~A}$ & $4.2 \pm 0.3 \mathrm{~A}$ & $5.0 \pm 0.6 \mathrm{AB}$ & $4.9 \pm 0.4 \mathrm{~A}$ & $3.9 \pm 0.5 \mathrm{~A}$ & $4.3 \pm 0.3 \mathrm{~A}$ \\
\hline Stem (g) & $5.4 \pm 0.5 \mathrm{D}$ & $2.9 \pm 0.2 \mathrm{~B}$ & $3.3 \pm 0.3 \mathrm{C}$ & $2.2 \pm 0.1 \mathrm{~A}$ & $3.9 \pm 0.4 \mathrm{C}$ & $1.9 \pm 0.2 \mathrm{~A}$ & $2.8 \pm 0.2 \mathrm{~B}$ & $1.8 \pm 0.1 \mathrm{~A}$ \\
\hline Leaf $(g)$ & $2.4 \pm 0.6 \mathrm{AB}$ & $3.1 \pm 0.4 \mathrm{~B}$ & $2.2 \pm 0.4 \mathrm{~B}$ & $2.6 \pm 0.3 \mathrm{~B}$ & $2.8 \pm 0.8 \mathrm{AB}$ & $2.7 \pm 0.3 \mathrm{~B}$ & $2.9 \pm 0.7 \mathrm{AB}$ & $1.7 \pm 0.3 \mathrm{~A}$ \\
\hline Dt_stem $(\mu \mathrm{m})$ & $23.1 \pm 3.8 \mathrm{C}$ & $14.8 \pm 2.1 \mathrm{~B}$ & $19.9 \pm 2.2 \mathrm{C}$ & $9.4 \pm 1.2 \mathrm{~A}$ & $22.6 \pm 4.1 \mathrm{C}$ & $13.6 \pm 1.5 \mathrm{AB}$ & $17.8 \pm 2.2 \mathrm{BC}$ & $10.2 \pm 1.5 \mathrm{~A}$ \\
\hline Dt_root $(\mu \mathrm{m})$ & $12.3 \pm 0.9 \mathrm{C}$ & $10.2 \pm 1.0 \mathrm{BC}$ & $11.8 \pm 1.3 \mathrm{C}$ & $8.8 \pm 0.8 \mathrm{AB}$ & $13.3 \pm 1.6 \mathrm{C}$ & $9.0 \pm 0.6 \mathrm{~B}$ & $10.7 \pm 1.1 \mathrm{BC}$ & $7.6 \pm 0.5 \mathrm{~A}$ \\
\hline Aerenchyma & Yes $-38 \%$ & No & No & No & Yes $-84 \%$ & No & Yes $-24 \%$ & No \\
\hline Root $_{\text {fine }} /$ Leaf & $0.72 \pm 0.09 \mathrm{~B}$ & $0.53 \pm 0.05 \mathrm{~A}$ & $0.74 \pm 0.10 \mathrm{~B}$ & $0.50 \pm 0.06 \mathrm{~A}$ & $0.71 \pm 0.12 \mathrm{AB}$ & $0.67 \pm 0.04 \mathrm{~B}$ & $0.48 \pm 0.07 \mathrm{~A}$ & $0.79 \pm 0.9 \mathrm{~B}$ \\
\hline LMA $\left(\mathrm{g} \mathrm{cm}^{-2}\right)$ & $9.1 \pm 0.9 \mathrm{~B}$ & $13.4 \pm 0.7 \mathrm{D}$ & $7.0 \pm 0.6 \mathrm{~A}$ & $11.8 \pm 0.5 \mathrm{C}$ & $8.9 \pm 1.0 \mathrm{~B}$ & $11.4 \pm 0.8 \mathrm{C}$ & $7.2 \pm 0.4 \mathrm{~A}$ & $9.0 \pm 0.6 \mathrm{~B}$ \\
\hline
\end{tabular}

Values in horizontal sequences not followed by the same letter are significantly different at the 0.05 level. 
Table 2: Mean root hydraulic conductance on a root-mass basis ( $\mathrm{K}_{\text {root_biomass }}$ ), root hydraulic conductance on a root-mass basis after inhibiting aquaporin (AQP) activity (AQP-inhibited $K_{\text {root_biomass }}$ ), leaf water potentials ( $\Psi_{\text {leaf }}$ ), stomatal conductance, light saturated photosynthesis, and photosynthetic parameters at $25^{\circ} \mathrm{C}\left(\mathrm{VC}_{\max 25}, \mathrm{~J}_{\max 25}, \mathrm{R}_{\mathrm{d} 25}\right)$ for the different treatments of Taxodium distichum and Pinus taeda. Values are means +SE (n=5-6).

\begin{tabular}{|c|c|c|c|c|c|c|c|c|}
\hline & \multicolumn{2}{|c|}{ Control } & \multicolumn{2}{|c|}{ Drought } & \multicolumn{2}{|c|}{ Flooded } & \multicolumn{2}{|c|}{ Flooded plus Salt } \\
\hline & T. distichum & P. taeda & T. distichum & P. taeda & T. distichum & P. taeda & T. distichum & P. taeda \\
\hline $\begin{array}{c}\mathrm{K}_{\text {root_biomass }} \\
\left(\mathrm{g} \mathrm{kg}^{-1} \mathrm{~s}^{-1} \mathrm{MPa}^{-1}\right)\end{array}$ & $8.6 \pm 0.3 \mathrm{C}$ & $9.6 \pm 1.1 \mathrm{C}$ & $5.9 \pm 0.4 \mathrm{~B}$ & $4.6 \pm 0.7 \mathrm{~A}$ & $8.0 \pm 1.2 \mathrm{C}$ & $5.4 \pm 0.7 \mathrm{AB}$ & $5.0 \pm 1.4 \mathrm{AB}$ & $3.3 \pm 1.2 \mathrm{~A}$ \\
\hline $\begin{array}{l}\text { AQP-inhibited } \mathrm{K}_{\text {root biomass }} \\
\qquad\left(\mathrm{g} \mathrm{kg}^{-1} \mathrm{~s}^{-1} \mathrm{MPa}^{-1}\right)\end{array}$ & $3.9 \pm 0.3 \mathrm{~A}$ & $5.6 \pm 0.7 \mathrm{~B}$ & $4.0 \pm 0.1 \mathrm{~A}$ & $3.8 \pm 0.7 \mathrm{~A}$ & $3.4 \pm 0.4 \mathrm{~A}$ & $5.1 \pm 0.6 \mathrm{~B}$ & $3.7 \pm 0.5 \mathrm{~A}$ & $3.1 \pm 0.7 \mathrm{~A}$ \\
\hline $\begin{array}{c}\text { Predawn water potential } \\
(\mathrm{MPa})\end{array}$ & $-0.32 \pm 0.02 \mathrm{~B}$ & $-0.24 \pm 0.01 \mathrm{~A}$ & $-0.78 \pm 0.07 \mathrm{C}$ & $-0.93 \pm 0.08 \mathrm{C}$ & $-0.31 \pm 0.02 \mathrm{~B}$ & $-0.39 \pm 0.05 \mathrm{~B}$ & $-0.71 \pm 0.09 \mathrm{C}$ & $-0.77 \pm 0.09 \mathrm{C}$ \\
\hline $\begin{array}{l}\text { Midday water potential } \\
\qquad(\mathrm{MPa})\end{array}$ & $-0.70 \pm 0.08 \mathrm{~A}$ & $-1.18 \pm 0.07 \mathrm{~B}$ & $-0.94 \pm 0.09 \mathrm{~A}$ & $-1.29 \pm 0.07 \mathrm{~B}$ & $-0.78 \pm 0.09 \mathrm{~A}$ & $-1.22 \pm 0.11 \mathrm{~B}$ & $-0.98 \pm 0.06 \mathrm{~A}$ & $-1.38 \pm 0.10 \mathrm{~B}$ \\
\hline $\begin{array}{l}\text { Stomatal conductance } \\
\left(\mathrm{g}_{\mathrm{s} \_\max }, \mathrm{mmol} \mathrm{m}^{-2} \mathrm{~s}^{-1}\right)\end{array}$ & $124 \pm 13 \mathrm{E}$ & $93 \pm 6 \mathrm{D}$ & $92 \pm 11 \mathrm{D}$ & $41 \pm 5 B$ & $115 \pm 7 \mathrm{DE}$ & $61 \pm 6 C$ & $49 \pm 9 B C$ & $25 \pm 3 \mathrm{~A}$ \\
\hline $\begin{array}{l}\text { Light saturated photosynthetic rate } \\
\qquad\left(\mathrm{A}_{\mathrm{sat}} \mu \mathrm{mol} \mathrm{m}^{-2} \mathrm{~s}^{-1}\right)\end{array}$ & $7.0 \pm 0.5 \mathrm{C}$ & $6.1 \pm 0.4 \mathrm{C}$ & $4.2 \pm 0.5 \mathrm{~B}$ & $4.3 \pm 0.6 \mathrm{~B}$ & $6.2 \pm 0.7 \mathrm{C}$ & $4.4 \pm 0.8 \mathrm{~B}$ & $3.3 \pm 0.5 \mathrm{~B}$ & $1.8 \pm 0.2 \mathrm{~A}$ \\
\hline $\begin{array}{l}\text { Rubisco carboxylation capacity } \\
\qquad\left(\mathrm{VC}_{\max 25}, \mu \mathrm{mol} \mathrm{m} \mathrm{m}^{-2} \mathrm{~s}^{-1}\right)\end{array}$ & $44.9 \pm 6.2 \mathrm{D}$ & $33.2 \pm 5.2 \mathrm{CD}$ & $25.3 \pm 3.4 \mathrm{BC}$ & $21.7 \pm 2.5 \mathrm{~B}$ & $34.9 \pm 3.8 \mathrm{CD}$ & $26.0 \pm 1.6 \mathrm{~B}$ & $10.8 \pm 2.4 \mathrm{~A}$ & $6.1 \pm 0.9 \mathrm{~A}$ \\
\hline $\begin{array}{l}\text { Maximum electron transport rate } \\
\qquad\left(\mathrm{J}_{\left.\max 25, \mu \mathrm{mol} \mathrm{m}^{-2} \mathrm{~s}^{-1}\right)}\right.\end{array}$ & $66.3 \pm 5.6 \mathrm{D}$ & $52.3 \pm 4.1 \mathrm{C}$ & $39.1 \pm 3.2 \mathrm{~B}$ & $32.5 \pm 3.3 \mathrm{~B}$ & $55.7 \pm 6.1 \mathrm{CD}$ & $38.6 \pm 5.2 \mathrm{~B}$ & $29.6 \pm 6.6 \mathrm{~B}$ & $13.3 \pm 1.4 \mathrm{~A}$ \\
\hline $\begin{array}{l}\text { Dark respiration rate } \\
\left(\mathrm{R}_{\mathrm{d} 25}, \mu \mathrm{mol} \mathrm{m} \mathrm{m}^{-2} \mathrm{~s}^{-1}\right)\end{array}$ & $0.22 \pm 0.04 \mathrm{BC}$ & $0.27 \pm 0.04 \mathrm{C}$ & $0.19 \pm 0.04 \mathrm{~B}$ & $0.17 \pm 0.02 \mathrm{~B}$ & $0.19 \pm 0.02 \mathrm{~B}$ & $0.23 \pm 0.04 \mathrm{BC}$ & $0.12 \pm 0.02 \mathrm{~A}$ & $0.10 \pm 0.01 \mathrm{~A}$ \\
\hline
\end{tabular}

Values in horizontal sequences not followed by the same letter are significantly different at the 0.05 level. 

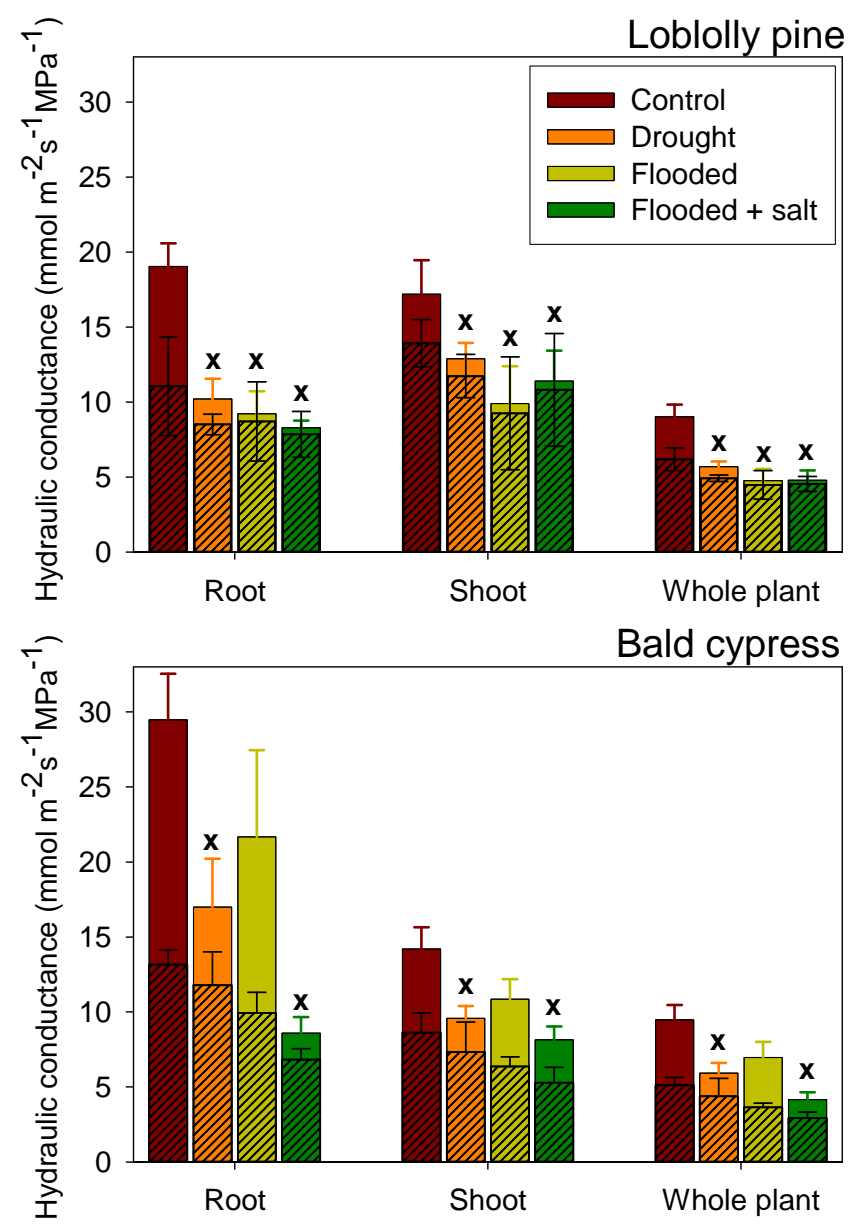

Figure 1: Mean values (+SE) of hydraulic conductances (solid bars) in root, shoot and whole loblolly pine $(n=6)$ and bald cypress $(n=5)$ plants growing in control, droughted, flooded and flooded + salt conditions. Crosses indicate a significant difference between control and any of the treatments $(p<0.05)$. Hashed bars represent values of hydraulic conductance following aquaporin inhibition i.e. the xylem-only part of the hydraulic pathway. 

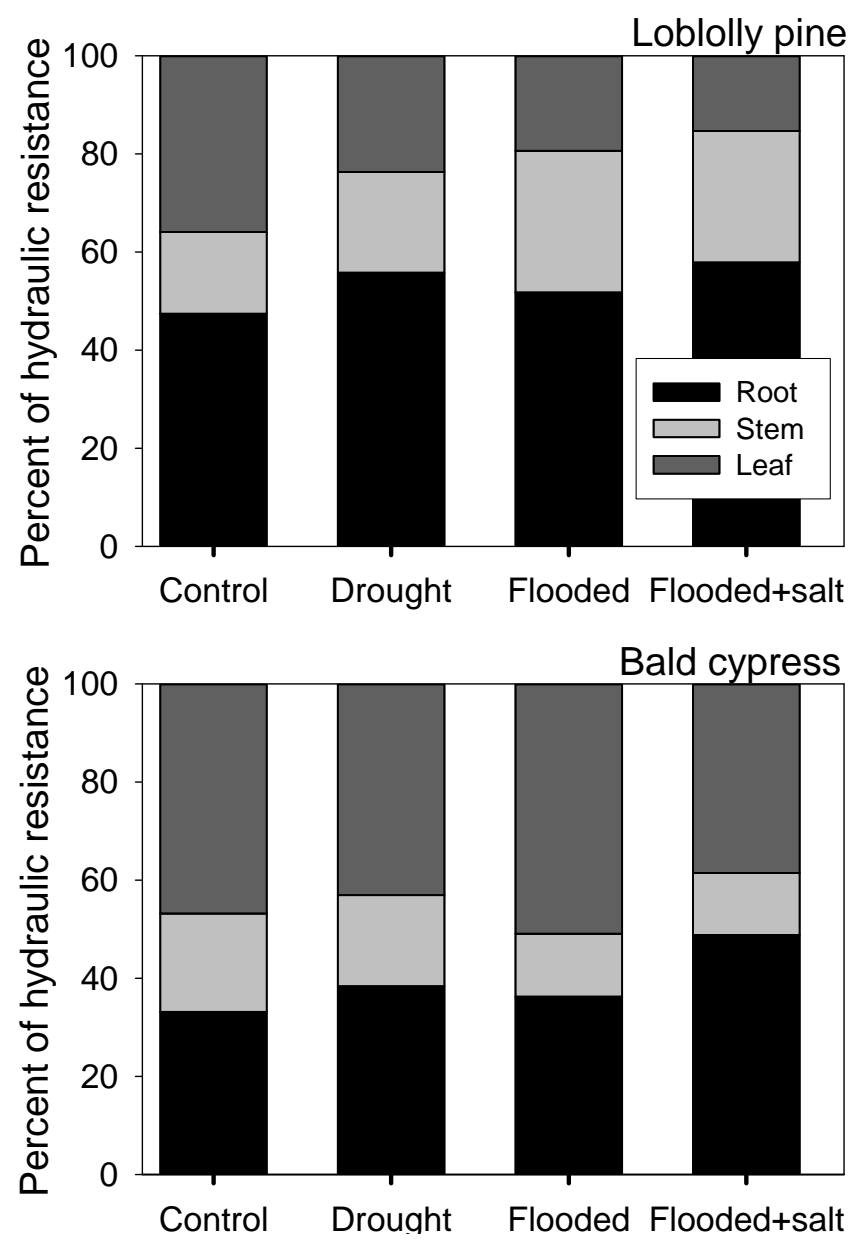

Figure 2: Partitioning of hydraulic resistances (1/conductance) of loblolly pine and bald cypress organs in control, flooded and flooded + salt conditions. Note that in all cases root and leaves represented more than $70 \%$ of total whole plant resistance. 

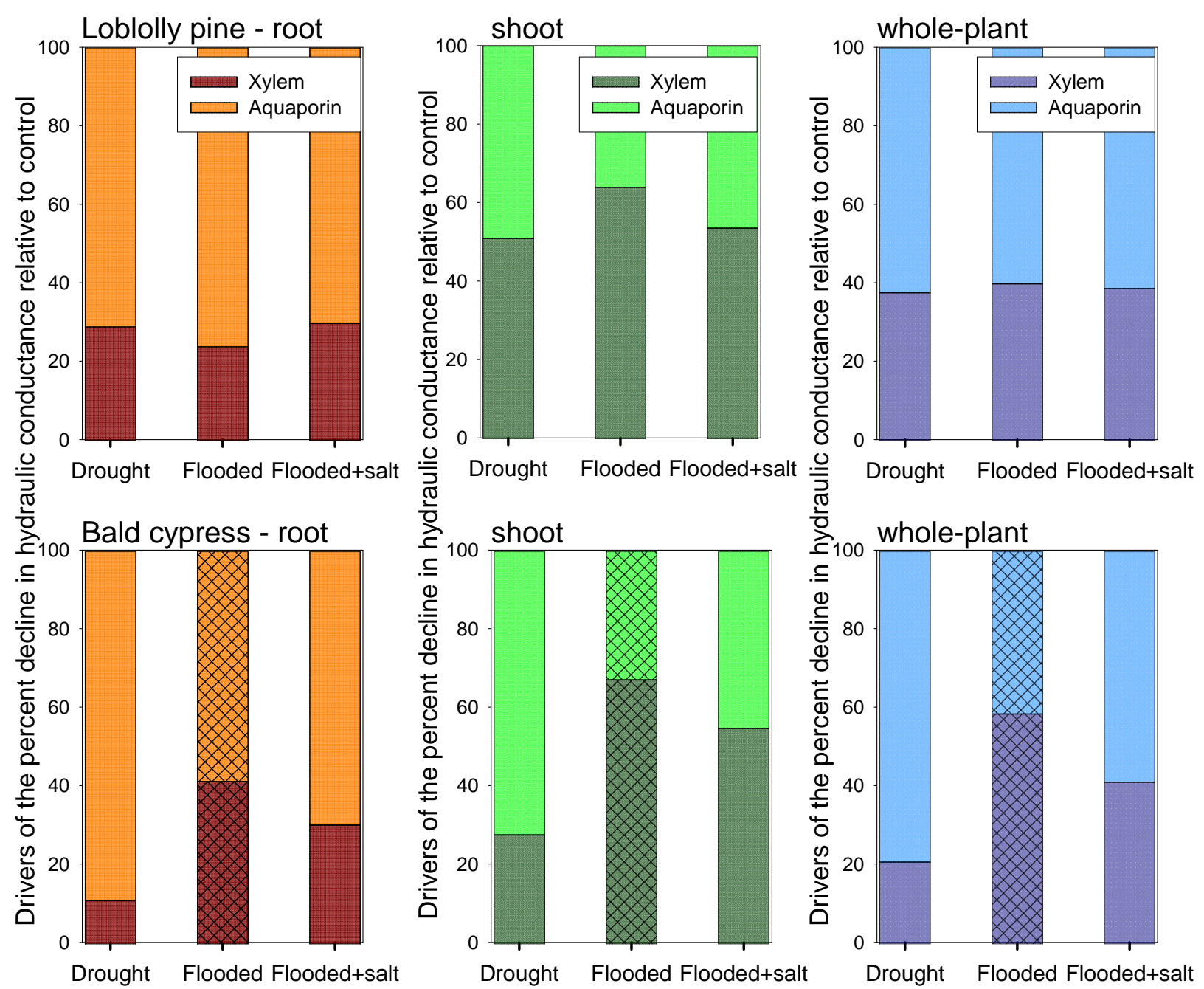

Figure 3: Effect (shown in percent) of either the xylem-only (structural changes in xylem conduits) or the aquaporin-only (AQP) part of the hydraulic pathway on the decrease in loblolly pine and bald cypress hydraulic conductance between control and drought, flooded, and flooded plus salinity treatments (absolute values of conductances are seen in Fig. 1). For a given stress applied, the structural part of the hydraulic pathway reducing conductance was calculated by dividing the difference in conductance between control and treatment after inhibiting AQP activity by the difference in conductance between control and treatment without inhibiting AQP activity. The AQP effect was taken as 1 minus the structural effect. Bars with patterns represent treatments that did not induce significant difference in conductance ( $p>0.05$; flooded condition for bald cypress). 

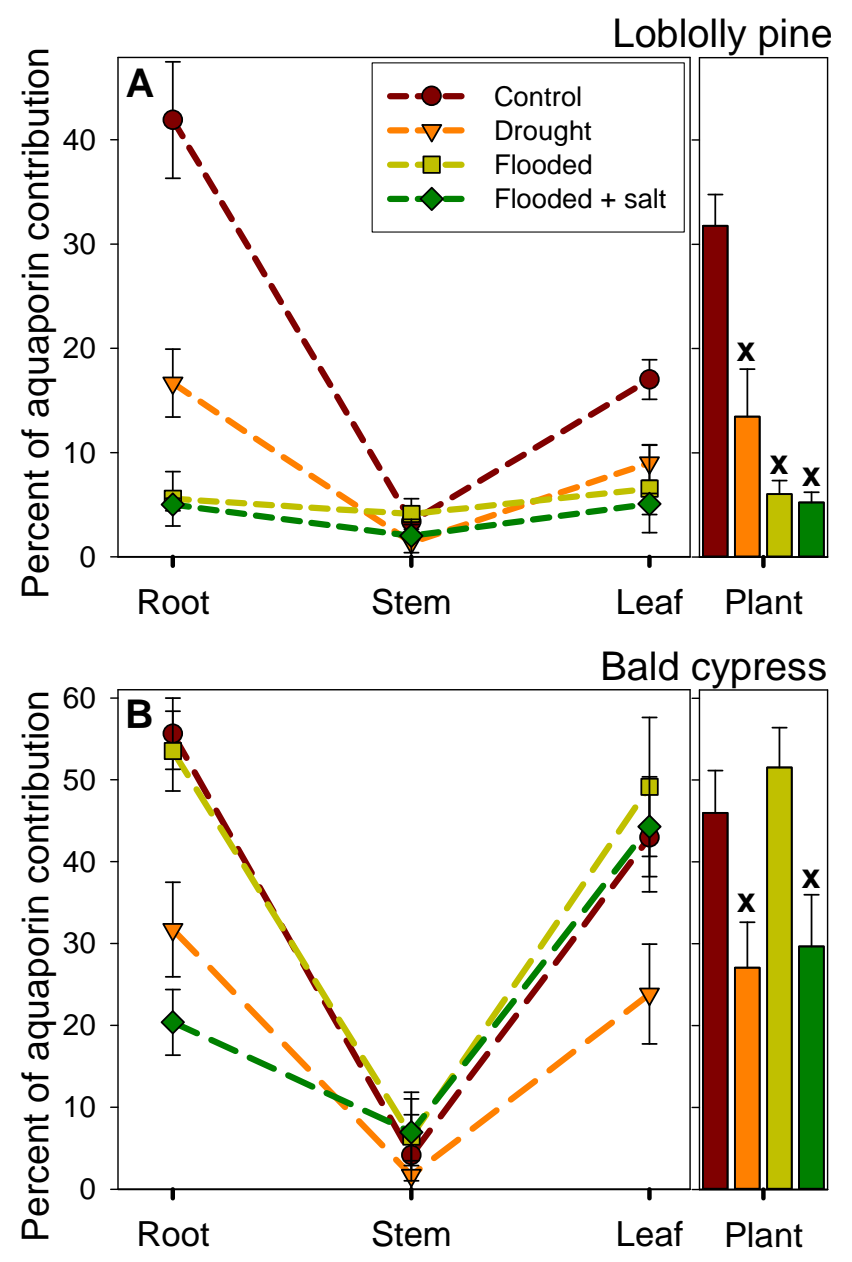

Figure 4: Aquaporin (AQP) contribution to root, stem, leaf and whole-plant hydraulic conductances in (A) loblolly pine $(n=6,+S E)$ and $(B)$ bald cypress seedlings $(n=5,+S E)$ growing under control, water-stressed, flooded, and flooded plus salinity conditions. Crosses indicate a significant difference in whole-plant AQP contribution between control and any of the treatments $(p<0.05)$. 

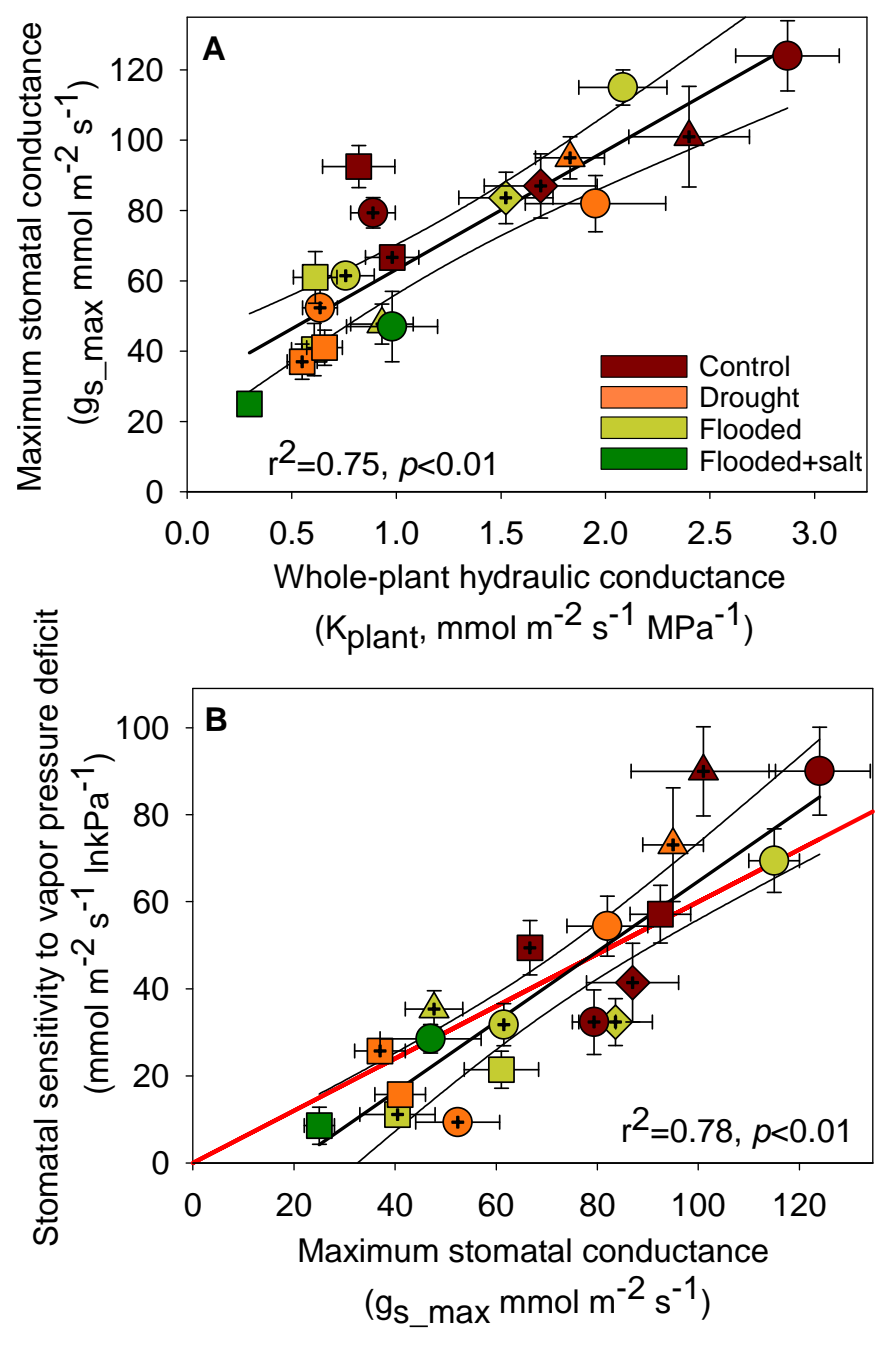

Figure 5: (A) Linear relationship between the maximum (reference) stomatal conductance $\left(g_{\mathrm{s}}\right.$ at vapor pressure deficit $=1 \mathrm{kPa})$ and $(B)$ plant hydraulic conductance $\left(\mathrm{K}_{\text {plant }}\right)$ and between the sensitivity of stomatal conductance to vapor pressure deficit $\left(\mathrm{dg}_{\mathrm{s}} / \mathrm{d} \ln \mathrm{VPD}\right)$ and $\mathrm{g}_{\mathrm{s}-\mathrm{max}}$ of plant species growing under control, water-stressed, flooded, and flooded plus salinity conditions. Circles, diamonds, squares and triangles represent bald cypress, water tupelo, loblolly pine and red maple, respectively. Crossed-filled symbols represent mature plants growing in the field, noncrossed symbols represent bald cypress and loblolly pine seedlings from the greenhouse experiment. In $(\mathrm{B})$, the red line (slope $=0.6$ ) indicates the theoretical slope between stomatal conductance at VPD $=1 \mathrm{kPa}$ and stomatal sensitivity to VPD that is consistent with the role of stomata in regulating minimum leaf water potential (Oren et al. 1999). 


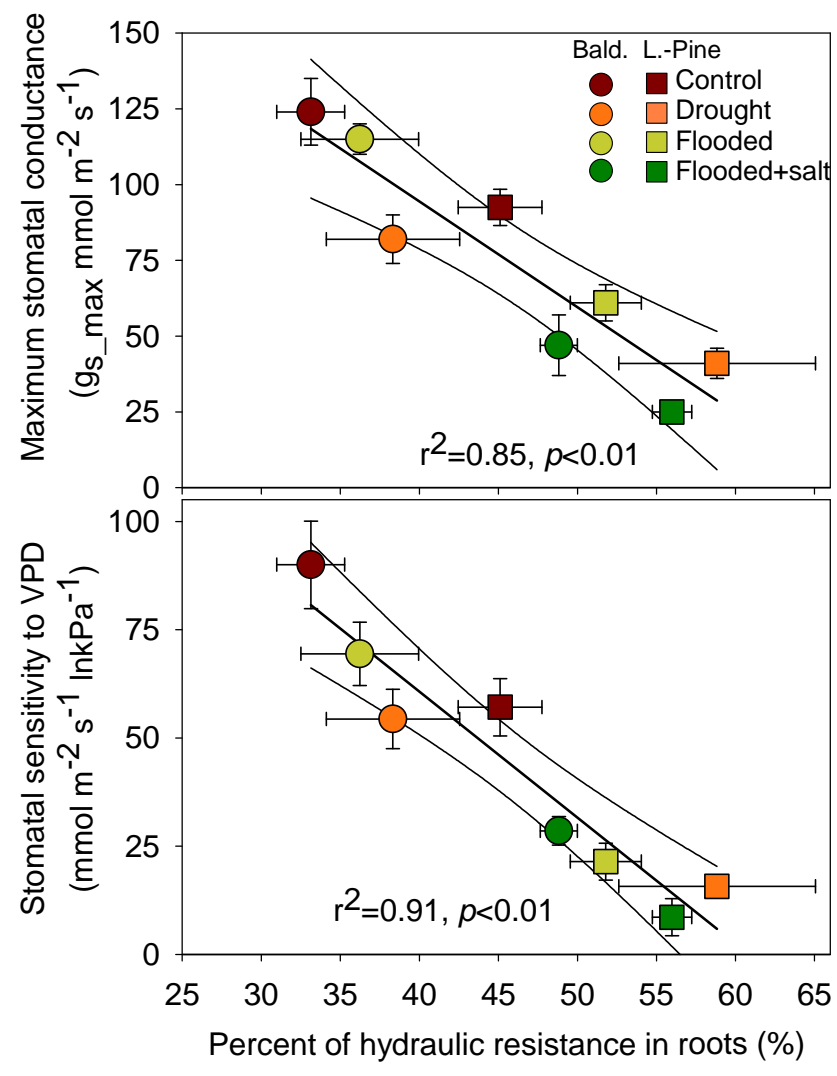

Figure 6: Maximum stomatal conductance ( $\left.\mathrm{g}_{\mathrm{s}-\mathrm{max}}\right)$ and the sensitivity of stomatal conductance to vapor pressure deficit $\left(\mathrm{dg}_{\mathrm{s}} / \mathrm{d} \ln \mathrm{VPD}\right)$ versus percent of hydraulic resistance in roots of bald cypress (Bald.) and loblolly pine (L.-Pine) seedlings growing under control, water-stressed, flooded, and flooded plus salinity conditions. 

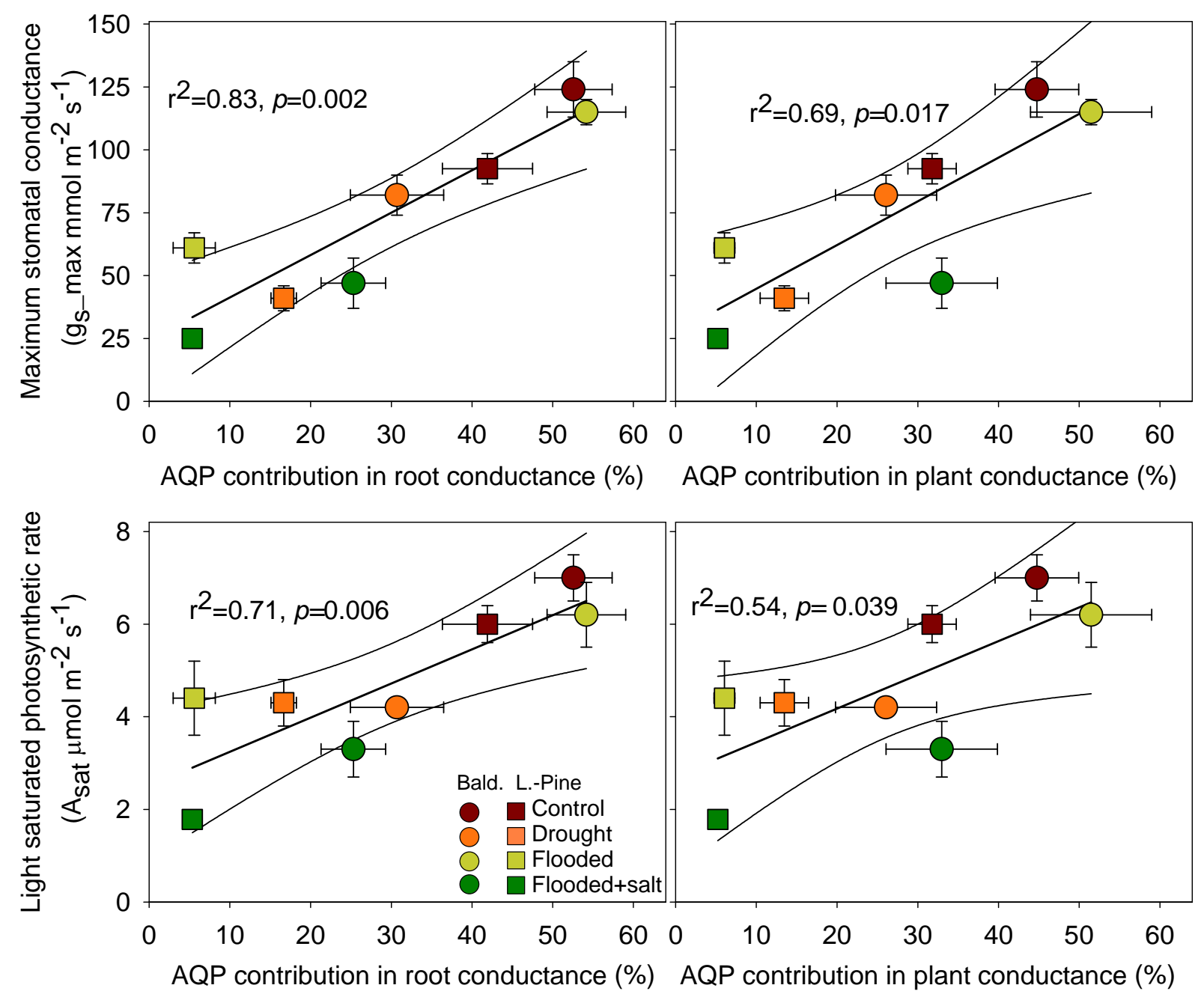

Figure 7: Maximum stomatal conductance $\left(\mathrm{g}_{\mathrm{s}-\mathrm{max}}\right)$ and light saturated photosynthetic rate (Asat) versus aquaporin (AQP) contribution to root, or whole-plant hydraulic conductances of bald cypress (Bald.) and loblolly pine (L.-Pine) seedlings growing under control, water-stressed, flooded, and flooded plus salinity conditions. 